$\mathcal{G S}_{\text {https://doi.org/10.3765/sp.10.2 }}^{\text {Semantics \& Pragmatics Volume 10, Article 2: 1-68, } 2017}$

\title{
Events, discourse representations and temporal reference*
}

\author{
Hans Kamp \\ Universität Stuttgart \\ University of Texas
}

Submitted 2014-07-03 / Early access 2017-03-27 / Final version published 2020-04-05

\begin{abstract}
This is the original English version of a paper that appeared in French translation nearly thirty-five years ago. The motivation for publishing the original version so long after the translation is in part historical. At the time when the French translation was published, the paper was intended as part of a triad, the other two members of which were Kamp 1979 and Kamp 1981a. But as the intervening years have made plain, for part of its potential readership the language of the translation has proved a hurdle, which publication of the original English should remove. The present paper is important as a kind of link between the other two papers. Kamp 1979 argued
\end{abstract}

* [This paper was prepared primarily from a copy of the English manuscript that was translated into French and abridged by Frédéric Nef for its appearance in Langages as Kamp 1981b. However, certain aspects of the French translation have been incorporated into this version. First, Nef added a number of footnotes to the Langages publication; many of these were aimed exclusively at his Francophone audience and are not included here, but others are likely to be helpful to English-speaking readers as well, and these have been retained as footnotes 11 and 26, which are bracketed and marked with Nef's initials and the original publication date. Second, Nef made certain changes to a number of the French examples. Some of those changes were confirmed as improvements by native speakers consulted in the preparation of the present version, and in those cases I have stuck to the Langages version, but otherwise the examples are as they were in the original manuscript; many thanks to Emilie Destruel-Johnson for her help with this. Nef's contributions mentioned above and also all he contributed to the project in private conversation, are hereby gratefully acknowledged. In addition to the aforementioned deviations from the original English manuscript, typographical errors have been corrected without comment; more substantive issues are addressed in bracketed footnotes tagged with the author's initials and the current year (like this one) or else in the preface to the appendix or in the postscript. In this connection, the author thanks Justin Cope. His assignment was to turn the document into S\&P's standard format; but his contributions have been of the kind you normally get (if you are lucky) from a colleague or an insightful and conscientious reviewer, and not from an editorial assistant. - HK, 2016]

(C)2017 Hans Kamp

This is an open-access article distributed under the terms of a Creative Commons Attribution License (https://creativecommons.org/licenses/by/3.o/). 
from a logical and philosophical perspective that in the analysis of temporal reference in natural languages times and events should be treated as first class citizens. The present paper was written as a follow-up to that paper, which made more explicit and expanded some parts of its predecessor that could not be included in its publication for reasons of length. In so doing it demonstrates the origins of Discourse Representation Theory: as a method for dealing with matters of tense and aspect, and not as a theory of "donkey pronouns", contrary to the widespread view that the reading of Kamp 1981a in isolation encourages.

The specific issues addressed in the present paper are the temporal and aspectual properties of the French tenses passé simple and imparfait. The central position underlying the treatment proposed is that these properties manifest themselves most clearly in the context of ongoing discourse: they determine, in different ways, how the content of a sentence in which they occur must be integrated into that of the antecedent sentence or discourse. (The discourse-oriented treatment developed in the paper has become the model for the analysis of tense and aspect within DRT generally.) The treatment of donkey pronouns, which came to be perceived as the mainstay of DRT in its early days, was "discovered" only after most of the material presented in the present paper was in place: donkey pronouns could be treated, it appeared, as nominal analogues of the anaphoric uses of tenses. But there are nevertheless important differences between Kamp 1981a and the present paper. In Kamp 1981a there is a strong emphasis on sentence-internal cases of donkey pronouns, those where they occur in logically embedded subclauses of complex sentences (such as the consequents of conditionals or the nuclear scopes of universal quantifications, like in Geach's "donkey sentences”). Logical embeddings are not considered in the present paper, although it is easy to see that tenses in subordinate clauses often behave in ways closely similar to donkey pronouns with sentence-internal antecedents. (A comprehensive DRT-based treatment of tenses in various types of subordinate clauses, in French or any other language, is missing to this day.) An extensive appendix to the paper develops the treatment proposed in the body of the paper in formal detail for a small fragment of French, whose (only) tenses are passé simple, imparfait and présent. A preface discussing some of the limitations of the fragment has been added to the appendix. Following this, a postscript expands on the paper's original aims.

Keywords: temporal semantics, tense, grammatical aspect, Discourse Representation Theory, passé simple, imparfait 
Events, discourse representations and temporal reference

I.

The present paper constitutes a first attempt to combine the ideas of one earlier essay, Kamp 1979, with the more rigorous treatment initiated by another, Kamp 1981a. It is a first attempt in at least two respects: in that the fragment of French which I will discuss here contains only a very small selection from the grammatical devices which the French language possesses; and also in that I am as yet uncertain about the range of applicability of the rules for processing temporal reference which I shall propose below.

To begin, let me summarize the content of the papers cited, to the extent that they are relevant to what I wish to accomplish here. There is one idea that is central to Kamp 1981a and which also permeates the later parts of Kamp 1979. This is the principle that the relation between the sentences, or sentence sequences, we employ in verbal communication and that which these sentences or sentence sequences are about are mediated by certain structures, which I have come to refer to as Discourse Representation Structures. These "representations", as I will often call them for short, are on the one hand determined by the syntactic structure of the sentences which they represent. On the other they have a form in virtue of which they can be linked to the subject matter of the sentences from which they derive in a very direct and intuitively plausible manner. Indeed, the linkage which we can thus establish, mediately, between the sentences which determine the representation and the world of which they intend to speak is much more satisfying conceptually than that which emerges when we attempt to state, as has been common in Davidsonian truth theory or in model-theoretic semantics of the by now familiar kind, ${ }^{1}$ the truth conditions of sentences by a recursion that operates on syntactic sentence structure directly. The simplicity of the link between representation and subject matter derives from the circumstance that, in a quite specific sense, representations are pictures of the world described by the sentences which determine them. In fact, from a formal point of view they are (at least in the simplest cases) like partial models consisting of (i) a universe of discourse, i.e., a set of entities, and (ii) a (partial) specification of what simple properties these entities possess and what simple relations obtain between them; in this they are like the models which have been employed in model-theoretic semantics to encode the totality of things about which the sentences purport to speak and of basic facts concerning these in terms of which those sentences can be evaluated as either true or false.

1 See, e.g., Davidson 1967, Evans \& McDowell 1976 or Montague 1970a, 197ob, 1973. 
This formal similarity between representations and models has the following significance: a given representation $\mathrm{K}$ is correct, and therewith the discourse which determines $\mathrm{K}$ true, relative to (a situation encoded by) a model $\mathcal{M}$ iff $\mathrm{K}$ can be seen as corresponding to some appropriate part of $\mathcal{M}$, i.e., iff there is a way of correlating the members of the universe of $\mathrm{K}$ with objects in the universe of $\mathcal{M}$ in such a way that the primitive properties and relations specified by $\mathrm{K}$ as holding of the members in its universe obtain in $\mathcal{M}$ of the correlated members from the universe of $\mathcal{M}$.

Truth, of a given sentence or discourse, with respect to a given world or situation is thus equated with the existence of an embedding of its representation in the model encoding the basic facts about that situation or world which preserves assignments of primitive predicates. (We shall refer to such preserving embeddings as proper, or as verifying embeddings.)

There is a sense implied by this definition of truth, in which the representation of a bit of discourse functions as a picture of reality, a picture that is correct iff it can be matched flawlessly with what it is a picture of by means of a correlation which, one might say, is in accordance with the "pictorial code" for this type of picture.

This last paragraph may have reminded the reader of certain passages in Wittgenstein's Tractatus (1922). I should hasten to add, however that, according to the theory developed in Kamp 1981a the matter is in general by no means as simple as Wittgenstein's picture theory suggests. Only when the discourse is comparatively simple does its representation determine the truth conditions in the straightforward sense just indicated. But as soon as a discourse contains sentences involving, e.g., hypotheticals or universal quantification, its representation has complexities which I have ignored here; as a consequence the correspondence between such representations and models is then a substantially more complicated matter too. In this paper I shall avoid these complications. (But see footnote 13 on page 33. A detailed discussion of these problems can be found in Kamp 1981a.)

Let us, lest all this remain entirely obscure, look at a few examples (cf. Kamp 1981a). 
Events, discourse representations and temporal reference

(1) a. Pedro owns Chiquita. He beats her.

b. DRS:

\begin{tabular}{|cl|}
\hline & \multicolumn{1}{c|}{$v$} \\
(1) & Pedro owns Chiquita \\
(2) & $u$ = Pedro \\
(3) & $u$ owns Chiquita \\
(4) & $v$ = Chiquita \\
(5) $u$ owns $v$ \\
(6) he beats her \\
(7) $u$ beats her \\
(8) $u$ beats $v$
\end{tabular}

By a model $\mathcal{M}$ (for the language in which (1a) is couched) we shall understand a pair $\left\langle U_{\mathcal{M}}, \mathscr{F}_{\mathcal{M}}\right\rangle$, where $U_{\mathcal{M}}$ is a nonempty set (the universe) and $\mathscr{F}_{\mathcal{M}}$ is a function which assigns to each of the nonlogical words of the language an appropriate extension relative to $U_{\mathcal{M}}$. Here the relevant nonlogical words are the names Pedro and Chiquita, to which $\mathscr{F}_{\mathcal{M}}$ must assign particular members of $U_{\mathcal{M}}$ (which will thereby count as the bearers of these names) and the transitive verbs (i.e., binary predicates) owns and beats, to which $\mathscr{F}_{\mathcal{M}}$ must assign sets of pairs of elements of $U_{\mathcal{M}}$ - the intuitive significance of the membership of $\langle a, b\rangle$ in, say, $\mathscr{F}_{\mathcal{M}}$ (owns) being that $a$ stands in the relation of ownership to $b$. The representation ( $1 \mathrm{~b}$ ) is correct (and thus the discourse (1a) true) with respect to such a model $\mathcal{M}$, iff there is a function $f$ which maps $u$ onto a member $a$ of $U_{\mathcal{M}}$ and $v$ onto a member $b$ of $U_{\mathcal{M}}$ so that all the atomic conditions in (1b) are true in $\mathcal{M}$ of the corresponding individuals $a$ and $b$. (Here by the atomic conditions of the DRS, I mean those which cannot be reduced any further in it. In (1b) these are the conditions numbered (2), (4), (5) and (8).) Thus $f$ must be such that (i) $a=\mathscr{F}_{\mathcal{M}}$ (Pedro), (ii) $b=\mathscr{F}_{\mathcal{M}}$ (Chiquita), (iii) $\langle a, b\rangle \in \mathscr{F}_{\mathcal{M}}$ (owns) and (iv) $\langle a, b\rangle \in \mathscr{F}_{\mathcal{M}}$ (beats). It should be clear that in this manner we assign to (1a) the truth conditions which it must have according to our linguistic intuitions. 
(2) a. Pedro owns a donkey. He beats it.

b. DRS:

\begin{tabular}{|l|}
\hline \multicolumn{1}{|c|}{$u$} \\
Pedro owns a donkey \\
$u=$ Pedro \\
$u$ owns a donkey \\
donkey $(v)$ \\
$u$ owns $v$ \\
he beats it \\
$u$ beats it \\
$u$ beats $v$ \\
\hline
\end{tabular}

The interpretation function of a model $\mathcal{M}$ with respect to which we can assess the correctness of (2b) must also specify an extension for the common noun, i.e., the unary predicate, donkey. An appropriate assignment to such a word is some subset of the universe $U_{\mathcal{M}}$, intuitively the set of all those elements of $U_{\mathcal{M}}$ which are donkeys. With respect to such a model $\mathcal{M}$, (2b) is correct, and thus (2a) true, iff there is a function $f$ associating $u$ and $v$ with members $a$ and $b$ of $U_{\mathcal{M}}$ such that the same conditions are satisfied as under (1) except that now we must have not that $b=\mathscr{F}_{\mathcal{M}}$ (Chiquita) but rather that $b \in \mathscr{F}_{\mathcal{M}}$ (donkey). Again, the truth conditions thus attributed to (2a) accord with our intuitions.

(3) a. Pedro loves a woman who owns a donkey. It kicks him.

b. DRS:

\begin{tabular}{l}
\multicolumn{1}{c}{$u \quad \underline{w}$ ب } \\
Pedro loves a woman who owns a donkey \\
$u=$ Pedro \\
$u$ loves a woman who owns a donkey \\
woman $(v)$ \\
$u$ loves $v$ \\
$v$ owns a donkey \\
donkey $(w)$ \\
$v$ owns $w$ \\
it kicks him \\
$w$ kicks him \\
$w$ kicks $u$
\end{tabular}


Events, discourse representations and temporal reference

(3a) is true, on the representation (3b), with respect to a model $\mathcal{M}$ (which must now provide appropriate extensions for the verbs loves, owns and kicks, for the common nouns woman and donkey and for the proper name Pedro), iff there is a function $f$ which maps $u, v, w$ onto $a, b, c \in U_{\mathcal{M}}$ such that $a=\mathscr{F}_{\mathcal{M}}$ (Pedro), $b \in \mathscr{F}_{\mathcal{M}}($ woman $), c \in \mathscr{F}_{\mathcal{M}}\left(\right.$ donkey), $\langle a, b\rangle \in \mathscr{F}_{\mathcal{M}}$ (loves), $\langle b, c\rangle \in \mathscr{F}_{\mathcal{M}}($ owns $)$ and $\langle c, a\rangle \in \mathscr{F}_{\mathcal{M}}($ kicks $)$. Once again the truth conditions, thus specified, are what they ought to be.

(4) a. A boy who admires her courts a girl who loves him.

b. DRS:

a boy who admires her courts a girl who loves him
boy $(u)$
$u$ courts a girl who loves him
$u$ admires her
girl $(v)$
$u$ courts $v$
$v$ loves him
$u$ admires $v$
$v$ loves $u$

According to our definition (4a) is true, on (4b) and with respect to a suitable model $\mathcal{M}$, iff there is a function $f$ mapping $u$ onto some $a \in U_{\mathcal{M}}$ and $v$ onto some $b \in U_{\mathcal{M}}$ such that $a \in \mathscr{F}_{\mathcal{M}}(b o y), b \in \mathscr{F}_{\mathcal{M}}($ girl $),\langle a, b\rangle \in$ $\mathscr{F}_{\mathcal{M}}$ (courts), $\langle a, b\rangle \in \mathscr{F}_{\mathcal{M}}$ (admires) and $\langle b, a\rangle \in \mathscr{F}_{\mathcal{M}}$ (loves). This is indeed, it would seem, the condition which we would regard as necessary and sufficient for the truth of $(4 \mathrm{a})$.

Whereas we defined, at least for DRSs of the comparatively simple sort exemplified by (1b)-(4b), what it is for a DRS to be correct with respect to a model $\mathcal{M}$, I have said nothing yet about the systematic connection between a DRS and the discourse D which determines it. Once more I must refer the reader to Kamp 1981a, where this connection is rigorously defined in terms of rules which determine the construction of the DRS from the syntactic structure of the sentences which make up D, or to the appendix of the present paper, which deals in detail with an in certain respects simpler fragment of French. The articulation of this connection presupposes of course a syntax for the language to which D belongs. This syntax must - as it must, I believe, in any other systematic theory of linguistic description - be stated 
independently of any other component of the linguistic theory of which it is part. There is as yet notoriously little agreement as to what the proper syntax for any natural language might be. However, it turns out that many of the details that differentiate between rival syntactic proposals that can be found in the present literature do not significantly affect the operation of the rules of DRS-construction which take their cues from the syntactic analysis of the sentences which they convert into representations. Certainly these differences are of no consequence for the comparatively simple discourses which we shall consider here. I shall therefore leave all questions that concern the syntax until the appendix. ${ }^{2}$

As the examples should already have revealed, the construction of the DRS involves the breaking down of the various sentences that make up the represented discourse in a succession of steps which reduce them to primitive conditions corresponding to their ultimate components; the direction of this process is the exact opposite of its syntactic synthesis: which particular rule is to be applied at any intermediate stage of the process to one of the conditions which represent that intermediate stage is determined partly (though not always uniquely) by what had been the last syntactic operation involved in forming the component of the sentence to which this condition corresponds. In particular, where this operation consists in the combination of a transitive or intransitive verb phrase with a singular term, the question of what rule is to be applied depends on the character of this term. There is a crucial difference, in particular, between the rules corresponding to "referent introducing" singular terms, such as proper nouns and indefinite descriptions, on the one hand and on the other the rule that must be applied when the term is an anaphoric pronoun. This latter rule does not introduce a new element into the universe of the DRS, but rather selects one from those that are already in that universe at the time the rule is applied. (In more complicated cases, created for instance by conditionals and universal quantifiers, the discourse referent to be selected by the rule must not only be already available but also occupy within the DRS an appropriate position relative to that of the pronoun to which the rule is being applied. Once again the interested reader should consult Kamp 1981a, in which the issue of when a referent becomes available and that of where it is positioned in the DRS

2 Kamp 1981a provides a syntax for the relevant fragment, formulated in the framework established in Montague 1970a, 1970b, 1973. But another framework would have been equally compatible with the the DRS construction specified here. 
Events, discourse representations and temporal reference

are both shown to be important to the explanation of certain familiar data concerning pronominal anaphora.)

II.

Although none of what we have so far discussed has anything to do with reference to time, it was an interest in temporal reference that led me to the notion of discourse representation and to the particular role which it is made to play in the theory outlined in section I. Let me quickly retrace this path, a tentative exploration of which can be found in Kamp 1979.

It is all too familiar how inextricably temporal reference is interwoven with the expression of what one commonly refers to as "aspect". Personally I do not know of any fully satisfactory general definition of what aspect is; but there are various linguistic phenomena which are standardly described as "aspectual", and if we stick to those particular bits of nomenclature we cannot but conclude that the purely temporal features of many common sentence forms are not easily separable from their aspectual features. One of the prime illustrations of this is the contrast which exists in French (and similarly in other Romance languages) between the tenses that serve to indicate pastness; viz., the imparfait on the one and the passé simple - and, more recently, the passé composé - on the other hand. ${ }^{3}$ The difference between these tenses is a longstanding concern of Romance grammarians, who have tried to articulate it in various ways; thus it has been said:

3 I should have preferred to avoid the passé composé entirely in this paper. Its analysis is more complicated than that of the passé simple, as a consequence of the fact that it served originally, and still serves in Modern French, a function which resembles that of the present perfect in English rather than that of the passé simple in French. This latter function of the passé simple, the passé composé appears to have taken over only fairly recently. As a consequence the passé composé now has two quite distinct roles, and the strategies which speakers employ for deciding which function is the intended one on any particular occasion of its use are, it seems, quite involved. At any rate I have no proper understanding of how they work. If I have not excluded the passé composé entirely, this is only because certain sample discourses below would have been very unnatural had I been forced to use the passé simple wherever modern French would prefer (or perhaps even require) the passé composé. However, it should be kept firmly in mind that, in so far as this paper says anything about the passé composé at all, it is only concerned with that one of its two functions which it shares with the passé simple. I shall, to avoid undesirable verbal clutter, often speak in the main text of the passé simple. But in all cases where I do, the reader should understand me as speaking simultaneously of the passé simple and of the passé composé in that capacity in which it has come to replace the passé simple in spoken French. 
(5) a. that the passé simple conveys punctuality, whereas the imparfait conveys durativity;

b. that the passé simple conveys that the action, event or state reported with its help has come to an end, or is "closed", whereas the imparfait conveys no such termination, and thus is "open";

c. that the passé simple serves to "carry the story forwards" whereas the imparfait does no such thing;

d. that the imparfait makes one see what is being reported so to speak "from inside", whereas the passé simple conveys a perspective from afar.

In each of these claims there is more than a grain of truth. But it is impossible to articulate what truth there is in them within the model-theoretic framework which emerged as part of the development of a branch of logic known as "tense logic" and which for about ten years seemed to constitute the only reasonably sophisticated formal means for analyzing the semantic properties of such linguistic devices for referring to time as the tenses of the verb, temporal adverbs such as now, on the first of May, often, soon, for several hours, since the beginning of the year, from five till seven and so on, or special "aspectual verbs" such as start, stop and continue. To see why this framework is so utterly unsuitable for the formal articulation of the observations on the difference between passé simple and imparfait I just listed it will be necessary to describe what that framework is like. And the best way to describe what it is like is to explain how it came about.

It came about as the model theory for logical systems which include beside the familiar apparatus of the propositional or predicate calculus also a number of so-called "tense operators" - sentential operators the application of which to any given sentence $\phi$ produces a compound sentence which is true at a time $t$ iff $\phi$ is true at some systematically related set of other times. Thus the past tense operator P forms when combined with the sentence $\phi$ a compound sentence $\mathrm{P} \phi$ which is true at $t$ iff $\phi$ is true at some time $t^{\prime}$ antecedent to $t$-thus we could, if we are not too fussy about the correlation between the formal calculus and actual English, read " $\mathrm{P} \phi$ " as 'it was the case that $\phi$ '. Another example is the operator $\mathrm{G}$ meaning 'it will always be the case that'; G $\phi$ is a sentence that is true at $t$ iff $\phi$ is true at all times that follow $t$. A model in which we can assess the truth values of such a sentence at a time $t$ must therefore not only be able to tell us which tense operator free sentences are true at $t$, and thus what the extensions are at $t$ of 
Events, discourse representations and temporal reference

the nonlogical terms of the language, but also the truth values of sentences containing tense operators, and therefore the extensions of these terms at other times than $t$. This suggests the following modification of the concept of a model we employed in section I: the model is to provide us with extensions of the nonlogical terms for arbitrary moments of time.

There are various equivalent means of encoding all this information. Here we shall pack it in the form of two functions $\mathscr{U}$ and $\mathscr{F}$ which together associate with each moment of time $t$ a model $\mathcal{M}_{t}$ of the sort considered in section I, i.e., (i) a set $U_{t}$ of entities and (ii) a function $\mathscr{F}_{t}$ which assigns to the nonlogical terms of the language appropriate extensions relative to $U_{t}$. It is convenient, moreover, to make the structure of time itself an integral part of the model, something we accomplish by defining a temporal model to be a triple $\langle\mathcal{T}, \mathscr{U}, \mathscr{F}\rangle$, where (i) $\mathcal{T}$ is a linear ordering - i.e., a pair $\langle T, \prec\rangle$ consisting of a set $T$ (of moments of time, intuitively) and an ordering relation $\prec$ (intuitively the relation which holds between times $t_{1}$ and $t_{2}$ iff $t_{1}$ is earlier than $t_{2}$ ) whose field is $T$; and (ii) $\mathscr{U}$ and $\mathscr{F}$ are functions of the kinds just described, whose domains are also $T$.

With regard to temporal models thus defined it is indeed possible to recursively describe the truth conditions of the sentences of various tense logical systems - systems which, as I already said, arise through the addition to nontemporal logical languages, such as the first order predicate calculus, of one or more tense operators. ${ }^{4}$ Note that what we are to analyze here is not the truth value of a sentence $\phi$ with respect to a temporal model tout court, but rather that of the truth value of $\phi$ with respect to $\mathcal{M}$ at a time $t \in T_{\mathcal{M}}$; evidently we cannot speak of the truth value of $\phi$ with respect to $\mathcal{M}$ absolutely, as the same sentence may in a given model be true at one time and false at another. We shall denote the truth value of $\phi$ with respect to $\mathcal{M}$ at $t$ as " $[\phi]_{\mathcal{M}, t}$ ".

When scholars with a keener interest in the mechanisms of temporal reference in natural language tried to use temporal models of the sort described above for the analysis of these mechanisms they soon found that such models did not encode the information they found they really needed. The difficulty they encountered arises for instance when one asks how the truth value of a sentence such as (6) is determined by the extensions of the verb plough.

(6) Yesterday Pedro ploughed from one o'clock till five.

4 For a discussion of some of the principal metamathematical results, see Burgess 1979. 
Example (6) is true now, at time $t_{0}$, with respect to a temporal model $\mathcal{M}$ of the kind described, we would feel compelled to say, iff, given that $t_{1} \in T_{\mathcal{M}}$ is the time when it was one o'clock in the afternoon before the day of that to which $t_{0}$ belongs, and similarly $t_{2} \in T_{\mathcal{M}}$ is the time of that same afternoon at which it was five o'clock, it is the case for each time $t$ between $t_{1}$ and $t_{2}$ that the individual in $U_{t}$ denoted by Pedro in $\mathcal{M}$ belongs to the extension at $t$ in $\mathcal{M}$ of the intransitive verb plough.

There seems to be something counterintuitive in this account of the truth conditions of (6). For what, we may want to ask, could it mean for an individual $a$ to belong to the extension of a verb such as plough at an "instant" of time $t$ if it isn't that $t$ is part of a period of time of which, as a whole, it is true to say that $a$ passed that period of time ploughing? It seems, in other words, that the question of whether $a$ ploughs at the instant $t$ is not a conceptually primitive question, but rather one which can only be answered, if at all, by consideration of more fundamental semantic facts. A notion of a temporal model which treats such questions as primitive would thus appear somehow misconceived.

In fact the problem is even more serious than these remarks indicate. It is highly dubious whether the truth conditions we have given are correct, even if we allow for the possibility that the notions with the help of which they are stated are themselves to be evaluated in more basic terms. The difficulty is this: typically a man who ploughs all afternoon will make a little pause here and there; and his making such pauses does not (provided they are small enough, and especially when they are necessitated by the very activity they interrupt - such as when, for instance, the plough must be cleaned or oiled after a given period of continuous service) make it false to say that he had been ploughing, say, from one till five. But while it would thus appear that (6) must be regarded as true under such conditions, it rather looks as if it could not be according the truth conditions which we stated for it above. For let $t$ be an instant which belongs to one of the pauses during which the ploughing was suspended. Does Pedro belong to the extension of the verb plough at $t$ ? One feels inclined to say no; for nothing Pedro did at $t$ itself, or for that matter, at times in its immediate temporal vicinity, was ploughing in the strict sense of the word. If this is the right answer, then the truth conditions as we stated them are wrong.

We may have a certain hesitation, however, to accept the answer, since there is a sense in which from the perspective of the entire afternoon Pedro was ploughing at $t$; but if this is a ground for hesitation it can be so only 
Events, discourse representations and temporal reference

because $t$ counts as a time of ploughing in virtue of being part of an extended period of time which we are, for presumably independent reasons, committed to regarding as one during which Pedro ploughed. Thus to count Pedro as belonging to the extension of plough at $t$ on these grounds is to concede that the truth conditions of (6) are irredeemably circular.

Whichever may be the true answer to this question, it should be evident that

i. such questions are not conceptually primitive, and

ii. even if we take it for granted that they can somehow be answered, their answers contribute to the truth conditions of various sentences which, it was hoped, should be analyzable in terms of these answers, in ways vastly more complex and far less "purely temporal" than those made available by the structure of the temporal models we have so far specified.

It should be stressed that this is by no means a conclusive reason for replacing, as Bennett \& Partee 1978 proposes, our instant-based temporal models with models which provide extensions of verbs with respect to intervals of time rather than durationless moments. In fact, by simply switching from instants to intervals we are sweeping a number of problems under the carpet. For instance, we may now take the model to specify directly whether Pedro belongs to the extension of plough with respect to the period of time from one till five of the afternoon preceding the day at which the sentence (6) is being considered. But we thereby only circumvent the vexing problem of what kind of interruptions of the activity in the course of that period are compatible with his belonging to the extension of plough with respect to it. Even so, it is, I hope, plausible in view of what has been said that someone who wants to concentrate on those systematic semantic relations that can be stated in purely temporal terms would deem it wise to simply sidestep this and similarly hairy problems. And the switch from instant to interval models is a natural and in many ways fruitful move to make for one so motivated.

Where $i$ is an interval of time, $a$ an individual and $\mathrm{P}$ a certain predicate, e.g., be asleep, there are at least three different ways in which $i, a$ and $\mathrm{P}$ can be extensionally related:

i. $a$ belongs to the extension of $\mathrm{P}$ throughout $i$;

ii. $a$ does not belong to the extension of P during any part of $i$; and 
iii. $a$ belongs to the extension of $\mathrm{P}$ during certain parts of $i$ but not during certain others.

The first situation is expressed in English by the simple sentence ( $7 \mathrm{a})$, the second by the sentence ( $7 \mathrm{~b})$, whereas the third demands some such circumlocution as, for instance, (7c).

(7) a. During $i, a$ was asleep.

b. During $i, a$ was not asleep.

c. During part of $i, a$ was asleep and during some other part he was not.

It is important to observe that if case (iii) obtains both (7a) and (7b) count as false. This shows that if the specification of the extension of $\mathrm{P}$ is to provide a basis for articulating the truth conditions of both (7a) and (7b), it must distinguish between the three cases (i), (ii) and (iii). The natural way to encode this threefold distinction is to provide for each basic predicate both a positive and a negative extension, relative to any interval $i$ : where $\mathrm{P}$ is a one-place predicate, that $a$ belongs to the positive extension of $\mathrm{P}$ relative to $i$ is to signify intuitively that $a$ satisfies P during the entire interval $i$; that $a$ belongs to the negative extension of $\mathrm{P}$ relative to $i$ is to mean that $a$ fails to satisfy $\mathrm{P}$ throughout $i$; and if $a$ satisfies $\mathrm{P}$ throughout part of $i$, but fails to satisfy it during some other part $a$ will be neither in the positive nor in the negative extension of P relative to $i$. In this way we are led to a kind of partial model, in a sense of partial that is related to, but not identical with, that in which I described representations as partial models in section I. The sense is rather that which has been analyzed in the study of vagueness. ${ }^{5}$

Formally we shall define an interval model as a structure $\langle\mathcal{T}, \mathscr{U}, \mathscr{F}\rangle$, where, as before, $\mathcal{T}$ is a linear ordering $\langle T, \prec\rangle, \mathscr{U}$ is a function which assigns a set to each interval determined by $\langle T, \prec\rangle, \mathscr{F}$ is a function which assigns to each interval $i$ and each primitive predicate $\mathrm{P}$ a pair of appropriate extensions - that is to say, where $\mathrm{P}$ is a one-place predicate, $\mathscr{F}(i, \mathrm{P})$ is a pair of disjoint subsets of $U_{i}$, where $\mathrm{P}$ is a binary predicate, $\mathscr{F}(i, \mathrm{P})$ is a pair of disjoint sets of pairs of members of $U_{i}$, and so forth. We shall assume moreover that the denotations of proper names are fixed independently of time - we shall assume, that is, that where $\alpha$ is a proper name, $\mathscr{F}(\alpha)$ is

5 See, e.g., Fine 1975 or Kamp 1975. 
Events, discourse representations and temporal reference

defined for $\alpha$ simpliciter, and that $\mathscr{F}(\alpha)$ is an individual belonging to $U_{i}$ for at least some $i: \mathscr{F}(\alpha) \in \cup_{i} U_{i}{ }^{6}$

The one notion occurring in this specification of an interval model that has not yet been defined is that of an interval of a linear order $\langle T, \prec\rangle$. The notion is the familiar one: $i$ is an interval of $\langle T, \prec\rangle$ iff $i \subseteq T$ and for all $t_{1}, t_{2}, t_{3} \in T$ if $t_{1} \prec t_{2} \prec t_{3}$ and $t_{1}, t_{3} \in i$, then $t_{2} \in i$. (It would be more in accord with existing terminology in topology to refer to such subsets of $T$ as convex subsets and to reserve the term interval for those subsets $i$ for which there exist $t_{1}, t_{2} \in T$ such that $i$ consists of all times of $T$ between $t_{1}$ and $t_{2}$-including or not including $t_{1}$ and/or $t_{2}$. I believe however that the terminology adopted here accords better with the terminological practice in temporal semantics.)

The intervals of $\langle T, \prec\rangle$ stand to each other in relations that are easily defined in terms of the relation $\prec$ between instants. In particular, we can define:

$$
\begin{gathered}
i_{1} \propto i_{2} \text { (or: } i_{1} \text { properly precedes } i_{2} \text { ) iff } \\
\text { for all } t_{1} \in i_{1} \text { and } t_{2} \in i_{2}, t_{1} \prec t_{2} .
\end{gathered}
$$

Another notion that will be also important in the next section:

$$
i_{1} \bigcirc i_{2} \text { (or: } i_{1} \text { overlaps } i_{2} \text { ) iff } i_{1} \cap i_{2} \neq \varnothing \text {. }
$$

6 This way of specifying the denotations of proper names, and of the extensions of predicates, may seem to lead to certain difficulties. Pedro was asleep during $i$ for instance might be regarded as simply false when $\mathscr{F}$ (Pedro) does not belong to $U_{i}$, or to any $U_{j}$ for $j \subseteq i$, on the strength of the principle that if Pedro didn't even exist during $i$ it must be false to say of him that he was asleep during that period. This is an awkward type of problem, to which neither the present way of defining temporal models nor any simple alternative appears to provide an entirely satisfactory solution. The best reply I can give here is that the contents of the sets $U_{i}$ should be conceived in a quite liberal manner: $U_{i}$ should be thought of as containing not only those individuals which exist during $i$ in a concrete sense - e.g., the sense in which a person exists during $i$ iff $i$ is included in that person's lifetime - but also all those individuals to which it is possible to refer in a sentence which ostensibly predicates something of them relative to $i$. The distinction between those individuals in $U_{i}$ which exist during $i$ in a strict sense and those members of the set which do not should then be drawn with the help of special predicates, such as for instance the existence predicate E, which is treated in extenso in Cocchiarella 1966. But in any case this is not the sort of problem with which I wish to be concerned here and so I shall ignore it. (The reader may consult Kamp 1976 for some more detailed discussion of these difficulties.) 
III.

Whether we assume that the fundamental facts are given in the form of a model with instants or one with intervals, there isn't any hope of explicating the contrasts between imparfait and passé simple (as articulated in (5a)-(5d) in section II). Take for instance the contrast according to which the imparfait conveys durativity, whereas the passé simple conveys punctuality. We should feel entitled to an explanation of this difference in terms of any such model, so long as the model encodes the facts in what appears to be a way that is independent of the particular linguistic forms that we use to speak about them. But what form could such an explanation take? The contrast between imparfait and passé simple should manifest itself as the difference in duration between the periods taken up by the things we report with the help of these two tenses: what is reported in the imparfait should be true in the model for some extended period of time, whereas what is reported in the passé simple should be true during some single isolated temporal point. That this cannot possibly be right follows from the simple observation that the very same fact can be reported in one context with the help of the one of these tenses and in another with the help of the other. Thus the same event, that of Mary's doing the dishes, will in one context, in which we list, in order, the various tasks which occupied her in the course of the afternoon, be reported in the passé simple, or, less portentously, in the passé composé, as in (10):

(10) D’abord, Marie a fait la vaisselle. Puis elle a nettoyé la salle de bains. Puis elle s'est reposée.

'First Marie did the dishes. Then she cleaned the bathroom. Then she took a rest.'

On the other hand we may want to mention her doing the dishes as part of the background against which we recount some other sequence of events, as in (11).

(11) Pierre entra dans la cuisine. Marie faisait la vaisselle.

'Pierre entered the kitchen. Marie was doing the dishes.'

Both (10) and (11) may be true, and stylistically correct, reports of what happened on the same afternoon in the same house. So in any model which encodes the factual information concerning that house on the day in question there will be just one maximal period during which Mary satisfies the 
Events, discourse representations and temporal reference

predicate expressed by the verb phrase faire la vaisselle. This period is either extended or it is punctual; it can't be both. Thus what justifies the use of the passé composé in (10) and of the imparfait in (11) must derive from something other than the actual duration of that period. What it depends on is how the period is viewed, not on how long it lasted in actuality; indeed this is something, I believe, which traditional grammarians have always quite clearly perceived: the difference between passé simple and imparfait is a difference in how we represent the events which they are used to report; or, more precisely, the function of these tenses is, in part at least, to provide guidance to the recipient of the discourse in which they occur as to how he is to represent the information this discourse contains. In fact this is true, as far as I can see, of many of the features of linguistic expressions and constructions that have come to be called "aspectual": they function as instructions as to the particular way in which the information that is conveyed with their help is to be "pictured". (I am in fact tempted to regard this as the decisive element that distinguishes aspectual functions from those that have modal or temporal significance. To define "aspect" in these terms alone, however, would nevertheless create considerable tension with existing terminological practices, and I shall therefore resist the temptation to offer this as a general characterization of aspect.)

But let us ask what forms these representation instructions could actually take. To answer this question we must first ask in what form coherent temporal discourse is represented. Let us, in this first attempt to clarify the issue, restrict our attention to past tense discourses only. ${ }^{7}$

For a start consider (10). It recounts a number of successive events: doing the dishes, cleaning the bathroom, having a rest. It appears to me, as I suggested already in Kamp 1979, that the way we process a discourse of this kind involves the successive introduction, into the representation which we build up as the discourse proceeds, of "events". These events are represented as (i) succeeding each other in time, and (ii) as the kinds of events they are said to be by the sentences which provoke their introduction. Thus, using much the same formalism for presenting discourse representations which we already employed in section I, the DRS provoked by (10) would look, I suggest, something like this:

7 In Kamp 1979, I imposed a similar limitation, and for the same reasons of expediency. 


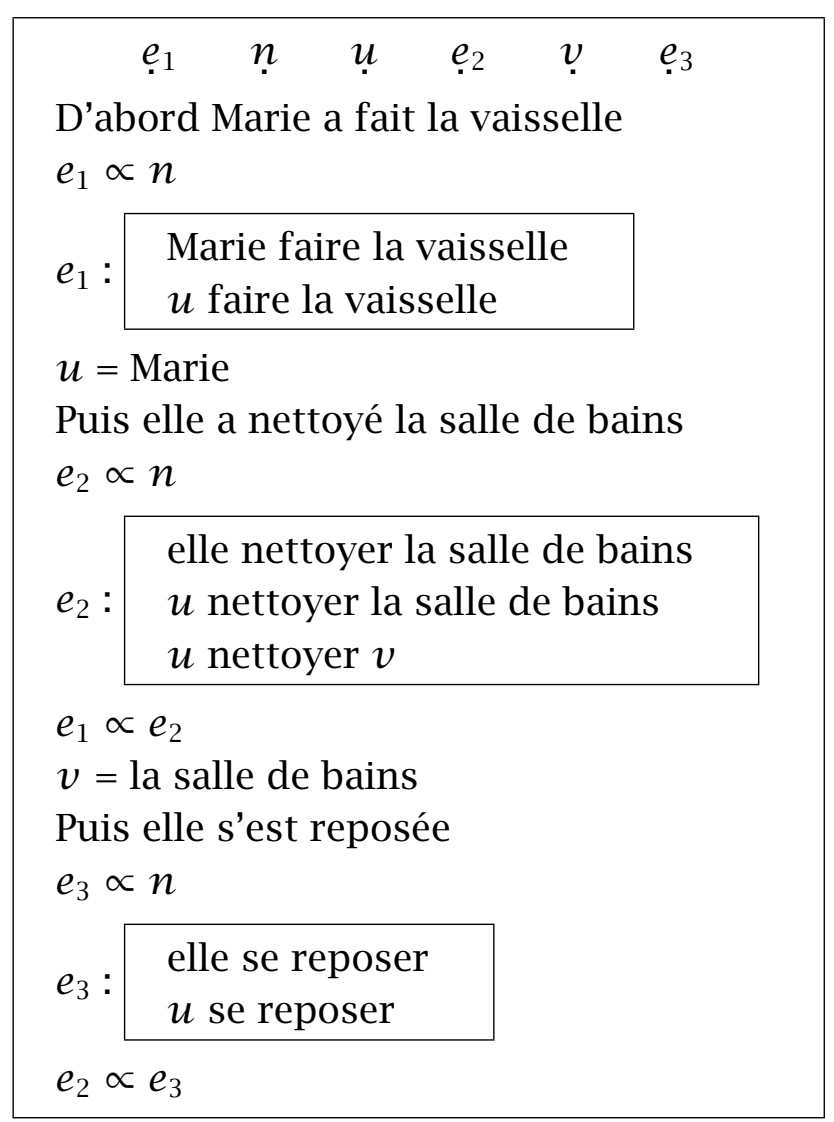

In this representation there is a "discourse event" $e$ for each of the three passé composé sentences which (10) contains. The temporal properties of these events are conveyed with the help of the relation $\propto$ which parallels the identically denoted relation of complete temporal precedence between intervals of $\mathcal{T}$, and which stands for complete temporal precedence between events and/or (interval-like or punctual) times. The temporal devices of (10), viz., the tenses of the verbs and the adverbs d'abord and puis together convey all the information which (12) encodes with the help of this symbol. In particular the "pastness" of the passé composé is represented by means of the conditions " $e_{i} \propto n$ ", with $n$ representing the time of speech (or, more generally, the time at which the discourse as a whole is to be evaluated). We shall come back to the particular role of $n$ when we come to discuss the question of truth conditions determined by representations such as (12). In addition, the events $e_{i}$ of (12) are specified as events of a certain individual performing a certain task. In the present example the specifications of these tasks are very simple and require few further reductions of the kind 
Events, discourse representations and temporal reference

illustrated by the examples of section I. But this need not be the case in general, and the fact that it is not always so requires, as we shall see later, very careful attention.

Let us contrast (12) with the DRS for an extension of (11), given in (13a). The DRS is presented in (13b), in the same format as (12):

(13) a. Pierre entra dans la cuisine. Marie faisait la vaisselle. Pierre passa au vestibule. Il ôta son manteau.

'Pierre entered the kitchen. Marie was doing the dishes. Pierre went into the hallway. He took off his coat.'

b. DRS:

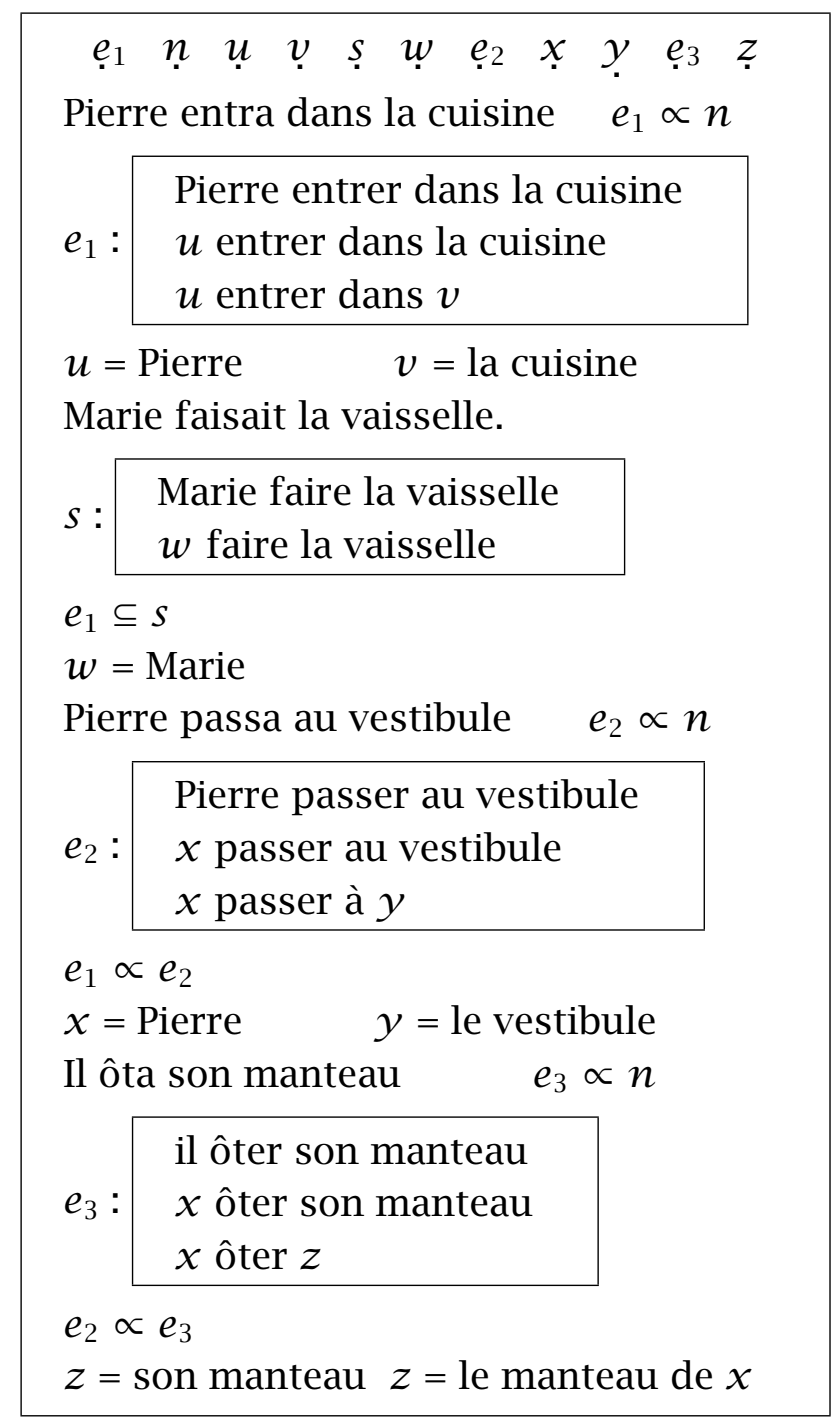


The only detail of this DRS that interests us at this moment is the representation of the second sentence of (13a), Marie faisait la vaisselle. We have represented the content of this sentence with the help of a "discourse state" which is specified as temporally including the last discourse event introduced in response to a passé simple sentence occurring in the antecedent discourse. This, it seems, is often the force of simple imparfait sentences in a narrative discourse in which such sentences occur together with simple sentences in the passé simple: the imparfait sentences following a given passé simple sentence $\mathrm{S}$ are typically understood as stating conditions which obtain at the time of the event $e$ which $S$ reports. Whether the state introduced by such an imparfait sentence outlasts the event with which it is presented as simultaneous is typically left undecided, thus in (13b) nothing commits us one way or the other in this regard. In fact, (13b) could have been continued on the one hand as (14a) or on the other as (14b).

(14) a. Puis il revint dans la cuisine. Marie faisait toujours la vaisselle.

'Then he returned to the kitchen. Marie was still doing the dishes.'

b. Lorsqu'il revint dans la cuisine, Marie avait fini de faire la vaisselle. 'When he returned to the kitchen, Marie had finished doing the dishes.'

These bits of discourse would provide information as to how much longer the state obtained, information which would be encoded in the DRS if and when the relevant bit is incorporated into it. But until then the matter is left open, and this is as it should be.

The possibility of continuing a discourse coherently in a manner which makes it plain that a discourse state temporally embraces a number of consecutive events is related to the "durative" aspect of the imparfait to which we referred once more at the beginning of this section. In this regard, we said, the imparfait is to be contrasted with the passé simple, which implies that the event it helps report is in some sense "punctual". Let us ask once more: what could this sense be?

Here then is an answer: the events reported by means of the passé simple are to be conceived as punctual. That is to say, the discourse events that are introduced into the DRS to represent them are to be treated as punctual within the temporal framework provided by the DRS itself. This means in particular that they should be preserved as temporally undivided wholes, which should not, either at the time of their introduction or afterwards, be 
Events, discourse representations and temporal reference

subdivided within the DRS through intersection with other discourse events, states or periods. It is tempting to state this principle in the guise of a formal constraint on further expansions of the DRS from the moment the given discourse event is introduced. In Kamp 1979 I gave way to this temptation, stipulating that when in the construction of the DRS of a past tense discourse of the sort illustrated by our examples a discourse event $e$ is introduced in response to a sentence in the passé simple then

(15) e may, neither at that nor at any later stage of the construction of the DRS, be temporally related to two other periods as in the following diagram:

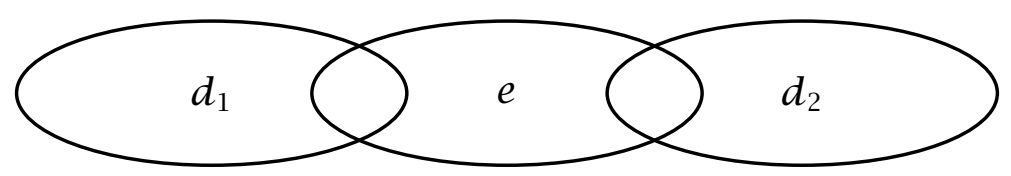

where $d_{1}$ and $d_{2}$ are events, states or intervals that are stipulated in the DRS as both overlapping $e$, while $d_{1}$ completely precedes $d_{2}$.

Indeed, a discourse event $e$ in a DRS in which (15) holds for $e$ can, in a quite natural sense, be shown to be punctual in the temporal structure provided by the DRS. Let me briefly summarize how this can be done. (Once again, for more details the reader might have a look at Kamp 1979.)

It was discovered during the early years of this century by Wiener (1914) that it is formally possible to regard the durationless elements of an "atomistic" linear ordering - such as the linear ordering of the real numbers which has been part and parcel of the theoretical apparatus of the natural sciences at least since the seventeenth century - as constructs defined in terms of an underlying structure of temporally related elements which need not be durationless themselves; in fact, the latter may reemerge as being of finite duration after the construction has been carried out - in the specific sense that to some or all of them there will then correspond an interval of the constructed linear ordering, all elements of which are, according to the natural definition of simultaneity which emerges from the construction, simultaneous with that element. Formally the construction is simple enough. Suppose that we are given a class $E$ of elements each two of which are related to each other by one or the other of two temporal relations, the relation $\bigcirc$ of overlap 
and the relation $\propto$ of complete precedence; and suppose that these relations satisfy the following postulates:

$$
\begin{array}{ll}
\text { A1: } & (\forall x, y)(x \propto y \rightarrow \neg y \propto x) \\
\text { A2: } & (\forall x, y, z)(x \propto y \wedge y \propto z \rightarrow x \propto z) \\
\text { A3: } & (\forall x)(x \bigcirc x) \\
\text { A4: } & (\forall x, y)(x \bigcirc y \rightarrow y \bigcirc x) \\
\text { A5: } & (\forall x, y)(x \propto y \rightarrow \neg y \bigcirc x) \\
\text { A6: } & (\forall x, y, z, u)(x \propto y \wedge y \bigcirc z \wedge z \propto u \rightarrow x \propto u) \\
\text { A7: } & (\forall x, y)(x \propto y \vee x \bigcirc y \vee y \propto x)
\end{array}
$$

Given the intuitive meaning of $\propto$ and $\bigcirc$ these postulates may seem natural enough. In fact, when we take $E$ to be the set of all intervals of a given linear ordering $\langle T, \prec\rangle$ and take $\propto$ and $\bigcirc$ to be the relations defined at the end of section II by (8) and (9), then A1-A7 are easily verified. Suppose on the other hand that we define an instant of the event structure $\mathcal{E}=\langle E, \propto, \bigcirc\rangle$ to be any maximal subset of $E$ of pairwise-overlapping elements:

$$
\begin{aligned}
& t \text { is an instant of } \mathcal{E} \text { iff } \\
& \text { i. } t \subseteq E \text {; } \\
& \text { ii. for every } e_{1}, e_{2} \in t, e_{1} \bigcirc e_{2} \text {; and } \\
& \text { iii. for each } e_{1} \in E \backslash t \text { there is an } e_{2} \in t \text { such that not } e_{1} \bigcirc e_{2} \text {. }
\end{aligned}
$$

Let $T_{\mathcal{E}}$ be the set of all instants of $\mathcal{E}$. Suppose further that for any two such instants $t_{1}$ and $t_{2}$ we define:

$$
t_{1} \prec_{\mathcal{E}} t_{2} \text { iff }\left(\exists e_{1} \in t_{1}\right)\left(\exists e_{2} \in t_{2}\right)\left(e_{1} \propto e_{2}\right)
$$

Then from the assumption that $\mathcal{E}$ satisfies A1-A7 we can derive that $\mathcal{T}_{\mathcal{E}}=$ $\left\langle T_{\mathcal{E}}, \prec_{\mathcal{E}}\right\rangle$ is a linear ordering. The intuition behind this construction is that the instants are obtained in the limit of a process by which we form ever shorter temporal intervals by intersecting ever larger collections of events which have a common temporal part (in the sense that no two elements in the collection fail to overlap). This intuitive explication of what goes on in definitions (17) and (18) shows that the elements of $E$ that belong, in the set-theoretic sense, to an instant $t \in T_{\mathcal{E}}$ should be thought of as precisely those which occur at the time $t$.

It is easily shown also that the set of instants at which a given element $e$ occurs, $\left\{t \in T_{\mathcal{E}}: e \in t\right\}$, is always an interval of $\mathcal{T}_{\mathcal{E}}$; we shall denote this interval as $\mathscr{D}(e)$. Moreover, an element $e$ may belong to many different 
Events, discourse representations and temporal reference

instants $t$; if $E$ is infinite, $\mathscr{D}(e)$ may turn out to be infinite for some $e$ of $E$ and even for every one of them. This will be so in particular if we take $E$ to be the set of all intervals of the real line that contain more than one point, and $\propto$ and $\bigcirc$ as the corresponding relations given by (8) and (9). In that case, moreover, $\mathscr{D}(e)$ will always be an interval of measure greater than zero, while at the same time even countably infinite sets of "instants" have measure zero.

There are various possible uses to which these formal results could be put. Russell (1914), who I believe to have posed the problem which Wiener solved in the manner sketched, was interested in it since his philosophical program at the time required all empirically significant concepts - such as in particular that of an instant of time - to be in some way analyzable in terms of elements directly accessible to consciousness. Such elements, be they sense data, experiences or perhaps mental events of some other kind, were supposed to have of necessity finite duration (for how else could we be directly aware of them) and so the problem arose how to construct out of them entities which were to be durationless even though their underlying components were not. But the application Russell intended is not by any means the only possible application of Wiener's result. Two other uses were discussed in Kamp 1979. There it was suggested in particular that the temporal structure encoded in a DRS constructed in response to, for instance, a bit of past tense narrative discourse can be seen as determining via Wiener's construction a temporal order of the form in which we have become accustomed to think of time, i.e., a linear order of instants. In fact, it is when we carry out this transformation that the formal significance of the constraint (15) on DRSconstruction becomes apparent: every event $e$ for which this constraint has been observed will reemerge, after the application of Wiener's procedure, as point-like, in the sense of occurring at one and one instant only.

As a matter of fact the last application of Wiener's theory is less straightforward than for instance the one which I suggested must have been intended by Russell. Where the elements of $E$ are all events in one and the same mind it is reasonable to assume that all postulates $\mathrm{A} 1-\mathrm{A} 7$, including the last one, are satisfied. But for the various temporal elements - events, states, times, periods - which are introduced into a given DRS it may well happen that their temporal relations are only partly determined. Here we cannot assume that A7 is always fulfilled. Where A7 fails, Wiener's construction cannot in general be shown to yield a linear ordering. The application of Wiener's procedure to the temporal structures directly encoded in the representations thus may lead to certain complications. In Kamp 1980 these are discussed at some 
length; one possibility is to consider the various ways in which the temporal relations between the elements of the DRS can be completed so as to produce structures which satisfy A7 as well as A1-A6 and to regard only those claims about the resulting time order as definite that can be obtained in this way. It should be noted in particular that a discourse event $e$ which satisfies (15) will reemerge as occurring at a single instant on each of these conversions.

I shall not pursue this problem any further here, however, not only because this would do no more than duplicate the discussions that can be found in Kamp 1979 and Kamp 1980 but also because principle (15) is in fact more suspect than I realized when these papers were written. Here for instance are two bits of discourse which lead to a violation of the principle and yet appear to be quite acceptable.

(19) a. Pierre dîna chez «Madame Gilbert». D’abord il y eut un hors d'œuvre. Puis du poisson. Après ça le gérant apporta un capon glacé. Le repas se termina par un dessert flambé, qui mit Pierre dans un état d'euphorie exceptionelle.

'Pierre had dinner at "Madame Gilbert". First there was an hors d'oeuvre. Then fish. After that the gérant brought a glazed capon. The meal ended with a dessert flambé that put Pierre in a state of exceptional euphoria.'

b. Pierre entra dans la chambre. Il fuma une cigarette. Dehors il pleuvait. Après quelque temps la pluie s'arrêta. Pierre fumait toujours.

'Pierre entered the room. He smoked a cigarette. Outside it was raining. After some time the rain had stopped. Pierre was still smoking.'

In (19a) the event reported by the first sentence, i.e., the entire meal, is subsequently subdivided into a number of "subevents", those corresponding to the individual courses. In (19b) the second sentence introduces an event, that of smoking a cigarette, which, as it turns out, continues after the change from raining to not raining.

I do not know at this time whether there are many other types of cases where a discourse event introduced by an assertion in the passé simple is subsequently displayed as temporally divided. But, whether or not additional types of contexts exist, (19b) in particular has shaken my hope that those discourses which violate (15) can all be seen to involve a certain "shift of 
Events, discourse representations and temporal reference

perspective", a certain thematic break after which an event which was at first conceived as punctual is subsequently seen from a different angle which reveals its internal structure. Nevertheless there are a great many discourse types in which the events reported in the passé simple are represented as discourse events that turn out to be punctual in the sense explicated above. But I am not sure as yet how to distinguish in a non-question-begging manner those types of discourse for which this holds true from those for which it does not.

Let us, before addressing the question of truth conditions for DRSs such as (12) and (13b), briefly consider the other contrasts between passé simple and imparfait which were mentioned in section II. Of the principle according to which it is the passé simple which pushes the action forwards we have already seen illustrations in (10) and (11). In both cases, we already observed, each next passé simple (or passé composé) sentence is understood as reporting an event subsequent to the last event introduced in response to a passé simple (or passé composé) sentence, whereas sentences in the imparfait do not have such an effect. But here too matters aren't quite as simple as this categorial claim implies. On the one hand, as has been recently observed in Hinrichs 1981, there are cases in which a sentence in the imparfait is understood as referring to a time following that of the last event introduced in response to a passé simple sentence:

(20) Pierre appuya sur l'interrupteur. Il faisait absolument noir, car les volets étaient tous fermés.

'Pierre pressed the light switch. It was pitch dark, since the shutters were all closed.'

On the other hand there are cases where a succession of sentences in the passé simple can be understood as reporting a number of simultaneous events. Thus consider (21).

(21) Cet été-là vit plusieurs changements dans l'existence de nos héros. Paul épousa Francine; Jean-Louis partit pour l'Afrique et Pedro s'acheta un âne.

'That summer saw several changes in the life of our heroes. Paul married Francine, Jean-Louis set off for Africa and Pedro bought himself a donkey.' 
There is no strong pressure to infer that the respective changes in the lives of Paul, Jean-Louis and Pedro must have occurred in that particular order. The liberty to understand the real order of occurrence of a number of events reported in the passé simple as possibly distinct from that in which they are being reported seems to arise in particular where the protagonists of those events are not the same. When several events concern one and the same person, it is often understood that they might not have happened at the same time. Moreover, the order of events would seem to constitute a significant part of the history of that individual. So it is not surprising that such reports should be governed by stricter principles, which correlate order of occurrence and order of report. But, plausible as this analysis of the difference between (21) and, say, (10) may seem, it is quite another matter to give it a sufficiently general and formal articulation which we could incorporate into a construction rule that determines precisely when the discourse event introduced by a new passé simple sentence must be marked in the DRS as subsequent to those introduced before.

The difference between (20) and, for instance, (11) would seem to lie in the causal nexus which appears to exist between the first and second sentence of (20), which is entirely absent in the case of (11). Here again one suspects the rudiments of a general principle. But I am hesitant to try and cast it in the form of a precise rule for, or constraint on, DRS-construction.

The principle that the passé simple, but not the imparfait, conveys "closedness" of the reported event is reflected by the construction rule according to which an event introduced by a passé simple sentence is always specified in the DRS as $\propto n$. States conveyed by sentences in the imparfait are not so marked, as illustrated by (13b). This, for once, appears to be a principle of quite general validity; at least I have not come across any evident counterexample to it. ${ }^{8}$

The fourth observation, that the imparfait conveys an internal and the passé simple an external perspective, is the most difficult to make sense of within the framework we have thus far developed. We use the passé simple when we want to look at the reported event from the perspective of some later time, a time which is conceived as lying unequivocally after the event, and from which the event appears as at some definite temporal distance in the direction of the past. It is for this very reason, in fact, that the events

8 [Contrary to what is suggested here, the construction rule for the imparfait that is presented in the appendix, CR.6, does in fact require states introduced by the imparfait to precede $n$. See footnote 32, page 53 for discussion of the apparent contradiction. - HK, 2016] 
Events, discourse representations and temporal reference

reported in this tense are typically viewed as completed and even punctual. Ordinarily this later vantage point is determined contextually as the time of utterance. But even in contexts which do not determine anything like a definite utterance time, as is common with literary texts, the type of viewpoint implied is nevertheless that from which the event is seen in retrospect.

The "internal" character of the perspective suggested by the imparfait seems to derive from the fact that this tense has as its main function that of shifting the perspective from the present to the past. Thus a sentence in the imparfait, such as e.g., that in (11), shows the interlocutor what the circumstances are at the time which the discourse has reached (which, as we saw, is often that of the last event $e$ introduced by a sentence in the passé simple) from the perspective of that very time - and thus, one is naturally tempted and often meant to infer, from the perspective of the individual or individuals involved in the events reported. Unfortunately the formal implications of this role of the imparfait become fully manifest only in the course of a careful analysis of the indexical features of temporal discourse and the proper way of encoding these at the level of discourse representation. This is an analysis which it would be quite impossible to carry out here, but which I hope to make available in the near future.

IV.

At long last we have reached the point where we can, and must, occupy ourselves with the truth conditions of temporal discourse. In section I, we saw how the truth of a discourse $\mathrm{D}$ in a model $\mathcal{M}$ could be characterized as the existence of an embedding of its DRS in $\mathcal{M}$ which shows that DRS to be a correct picture of the facts which $\mathcal{M}$ encodes. Evidently it would be unfortunate if we should have to abandon this characterization of the concept of truth for discourses other than those which involve the present tense only. So, let us suppose that the truth of a discourse such as (10) is to consist in the embeddability of its DRS; and let us suppose also that its DRS has the form of (12) and that, as we assumed in section I for the examples discussed there, a proper embedding of (12) must associate appropriate entities of the model with each of the elements of the universe of the DRS. Some of these elements are "discourse events" and some are "discourse times". The embedding should associate with these discourse referents entities in the model which are of the same kinds. Thus, in order that (12) can be properly 
embedded in a model $\mathcal{M}$ there must be among the entities of $\mathcal{M}$ in particular times and events.

It would be simple enough, of course, to stipulate that the universes of $\mathcal{M}$ are to contain events as well as individuals of other sorts. But by itself that will not do. For evidently the model must also provide specifications of what sorts of events its various events are. So we must ask: what properties and relations should the model explicitly ascribe to its events? Here we may take our clue from the representations for tensed discourse we have so far considered. Example (12) for instance shows the discourse events as entering into relations of, roughly, two types:

i. temporal relations with other events, as well as with times (e.g., $n$ );

ii. the relations that are expressed by those boxed parts of the DRS which are separated from the discourse events by colons.

Let us consider the temporal relations first. Events, we noted, have to be specified as temporally related not only to each other but also to times. Now times our model already contains, but not in the place set aside for individuals. The special position of times in instant and interval models arose through the transition to those kinds of models from the models considered in section I, which provide information about one time only; and it is a position that seems justified in view of the undoubtedly special role which times play in the semantics of tensed discourse. If it is right, however, to assign a special place to times then, we must ask, should events not be assigned a special place as well? For as we already noted, the traditional conception of time as a linear order of instants is highly problematic and it may well be held that we can only make sense of this notion if we see it as somehow grounded in an underlying structure of events. If we see events in the light of this function, then it becomes natural to make them occupy a similarly distinguished place in our models that we have already accorded to times.

Wiener's construction gives us a way, we saw, of obtaining instant structures from underlying event structures. But even if we take events as fundamental, it is by no means evident that times should be related to them in precisely the way that his construction describes. (There might for instance be excellent theoretical grounds for assuming the instant structure to be like the real numbers, although Wiener's construction yields, when applied to an independently given structure of events, only an instant structure that 
Events, discourse representations and temporal reference

isomorphic to the rationals.) Precisely how instants and events are related need not - and in fact it should not - be decided here. The only assumption we shall make is that instants and events are so related that an application of Wiener's construction to the set of events will not lead to new instants. To be precise, we shall assume as part of any model $\mathcal{M}$

i. an event structure $\mathcal{E}_{\mathcal{M}}=\left\langle E_{\mathcal{M}}, \propto_{\mathcal{M}}, \bigcirc_{\mathcal{M}}\right\rangle$,

ii. an instant structure $\mathcal{T}_{\mathcal{M}}=\left\langle T_{\mathcal{M}}, \prec \mathcal{M}\right\rangle$, and

iii. a function $\mathscr{D}_{\mathcal{M}}$ which assigns to each event $e \in E_{\mathcal{M}}$ an interval, viz., the set of all instants at which $e$ "goes on"; clearly $\mathscr{D}_{\mathcal{M}}$ must be assumed to be compatible in the sense that we always have
a. $e_{1} \propto_{\mathcal{M}} e_{2}$ iff $\mathscr{D}_{\mathcal{M}}\left(e_{1}\right) \propto_{\mathcal{T}} \mathscr{D}_{\mathcal{M}}\left(e_{2}\right)$ and
b. $e_{1} \bigcirc_{\mathcal{M}} e_{2}$ iff $\mathscr{D}_{\mathcal{M}}\left(e_{1}\right) \bigcirc_{\mathcal{T}} \mathscr{D}_{\mathcal{M}}\left(e_{2}\right)$

where $\propto_{\mathcal{T}}$ and $\bigcirc_{\mathcal{T}}$ are defined in terms of $\mathcal{T}_{\mathcal{M}}$ via the specifications (8) and (9). ${ }^{9}$

A model possessing the components (i)-(iii) will allow us to interpret discourse times and events as well as the temporal relations which the DRS specifies as holding between them. But it will not, as yet, provide us with any clear means of verifying whether an event satisfies any of the nontemporal conditions that the DRS specifies for the corresponding discourse events. How should the data on the basis of which such questions are to be decided be included in the model? The first problem we face here is how complex specifications of events should be reduced to their basic components. Here the form of our DRSs may serve as a guideline. A map $f$ will properly associate an event $e^{\prime}$ of the model $\mathcal{M}$ with the discourse event $e$ of the DRS K if $e^{\prime}$ satisfies in $\mathcal{M}$ all those irreducible conditions in which $e$ figures, and thus in particular those atomic conditions which occur in the nontemporal specification of $e$ in K. So $\mathcal{M}$ will have to be explicit only about such irreducible conditions.

9 Once again we avoid the complications which arise out of the circumstance that the temporal location of certain events (relative to each other, or relative to independently identified times) may not be fully determined. There are various ways in which these complications might be handled, but to go into details here would introduce complexities which it would take too long to expound and which would risk to obscure the main issues that are important here. 
What are such irreducible event specifications like? (12) gives us a few examples. The discourse event $e_{1}$, for instance, involves only one irreducible condition, viz., the condition $u$ faire la vaisselle. The model in which (12) is to be embedded must thus decide for any pair $\left\langle e_{1}^{\prime}, a\right\rangle$ consisting of an event $e_{1}^{\prime}$ and an individual $a$ whether $e_{1}^{\prime}$ is an event of $a$ doing the dishes. Similarly, the question whether (12)'s $e_{2}$ can be properly mapped onto an event $e_{2}^{\prime}$ of the model reduces to the question whether $e_{2}^{\prime}$ is an event of $a$ 's cleaning $b$, where $a$ and $b$ are the mapping targets of, respectively, the discourse referents $u$ and $v$. Let us suppose that these bits of information are encoded in the model as sets of finite tuples, each consisting of an event and one or more other individuals, which are assigned to certain verbs. Thus faire la vaisselle will be assigned a set of pairs $\left\langle e^{\prime}, a\right\rangle$ consisting of an event $e^{\prime}$ which is an event of $a$ 's doing the dishes; similarly, nettoyer will be assigned a set of triples $\left\langle e^{\prime}, a, b\right\rangle$ and so on.

The question which this raises is: which "verbs" should be assigned such sets of tuples? There are two aspects to this question:

i. Presumably only such verbs should be given "extensions" of this sort as are used to "report events". Which verbs are these precisely?

ii. The model should provide such extensions only for those verb phrases which are semantically primitive, i.e., those whose meanings do not reduce in a systematic way to the meanings of their components.

We will consider the second of these two questions first. The complexity of this question is not apparent from the few examples I have presented; and in fact it does not really manifest itself within the boundaries of the particular fragment which is given explicitly in the appendix and to which most of those particular examples belong. But it does arise in larger fragments, and it may be just as well if I give some indication of the problems one is to encounter there.

Where these arise they already arise at the level of representation. Consider, by way of illustration, the following two sentences:

(22) a. Pedro beat Chiquita with a whip in front of the stable.

b. Pedro gave presents to all his donkeys.

What should the DRS of (22a) be like? The one issue that we must address here and that hasn't already been settled by the earlier examples of DRSs (12) and (13) concerns the treatment of the prepositional phrases with a whip and 
Events, discourse representations and temporal reference

in front of the stable. The latter, locative, phrase is most naturally analyzed as a direct predication of the whipping event. This predication can be broken down, moreover, into the relation expressed by the preposition in front of and the prepositional object term the stable.

Probably it is right to analyze the instrumental phrase with a whip in the same way as I just proposed one should analyze the locative phrase - to analyze, that is, with a whip as a predication of the event, and possibly, with as expressing a relation between the event and the instrument, i.e., the particular whip, in question. This yields the following DRS.

e $\quad$ u $\quad$ u
$e \propto n$
$\begin{aligned} & \text { Pedro beat Chiquita with a whip in front of the stable } \\ & u \text { beat Chiquita with a whip in front of the stable } \\ & u \text { beat Chiquita with a whip } \\ & u \text { beat Chiquita } \\ & u \text { beat } z\end{aligned}$
$u=$ Pedro
$v=$ the stable
$e$ in front of $v$
whip $(w)$
$e$ with $w$
$z=$ Chiquita

But whether or not this is the correct treatment of instrumental phrases, it cannot be right for all prepositional phrases. Consider for instance the preposition by means of. Phrases formed with the help of this preposition are typically "intensional" in that what they contribute pertains specifically to the particular verb in terms of which the event is identified. Thus it could be argued that in a case where a dictator intimidates the inhabitants of his country by hanging a known innocent, the event of his intimidating the population is the very same as that of his hanging the innocent man. Yet, while it seems perfectly acceptable to use (24a) with reference to this situation, the statement (24b) is as odd here as it would be under any circumstances. ${ }^{10}$

10 See, e.g., Hornsby 1978. 
(24) a. The dictator intimidated the inhabitants by means of a public hanging.

b. The dictator hanged $x$ by means of a public hanging.

The phenomenon which this example illustrates manifests itself also, and in fact more commonly, in connection with adverbials which do not take the form of prepositional phrases. A familiar example is that of a person, $x$, who sets the swimming record for crossing the Channel, an event which justifies the statement (25a).

(25) a. $x$ swam across the Channel quickly.

b. $x$ crossed the Channel quickly.

Now let us suppose that $x$ crosses the Channel regularly, but normally by ferry or hovercraft, so that for a crossing of $x$ this particular crossing was not fast at all. Thus the statement (25b) may be false in the very context in which (25a) is true. ${ }^{11}$

The sensitivity of the adverb quickly to the verb used to describe the action is evidently of the same making as the well-documented sensitivity of most adjectives to the nouns with which they combine: ${ }^{12}$ as we use the adjective big, a big flea does not count as a big animal; similarly a good father need not be a good husband, even though he is a husband as well as a father. In much the same way, a fast swimming can, although it is also a crossing, fail to be a fast crossing. In Kamp 1975 I suggested that such sensitivity can be seen as a sensitivity of the adjective to the context of use, where that context is often largely or wholly determined by the noun which governs the adjective where it is used prenominally. Klein 1981 elaborates and improves upon this idea for a substantial class of adjectives, to which belong in particular, big and quick. Within a setting in which adverbs are treated as predicates (which is in fact what we have suggested here for the adverbs that are part of event reporting clauses) their sensitivity can be handled in a similar way. However to incorporate the technical apparatus of, say, Kamp 1975 into the general framework employed here would much complicate our exposition and to no particularly good purpose.

11 [The point here is that the crossing reported in (25b) was objectively faster than that reported in (25a). On these problems, cf. Davidson 1980: 103-205. - FN, 1981]

12 See, e.g., Montague 1970a, 1970b, 1973, Kamp 1975, Klein 1981. The point was also made by Terence Parsons as far back as 1967. [I have since learned from Barbara Partee that Parsons had published related observations in Parsons 1970. - HK, 2016] 
Events, discourse representations and temporal reference

Example (22b) raises issues other than those we encountered in our discussion of (22a). It seems to give a report of an event which can be regarded as a composite of many smaller events, each one consisting of the giving of a present to one donkey. There would be no particular problem about representing (22b) as saying neither more nor less than that for every one of Pedro's donkeys there was a present he gave to it. ${ }^{13}$

13 The representation of propositions that contain universal quantifiers creates certain complications which I prefer not to discuss in detail here, but an exact account of which can be found in Kamp 1981a. Very briefly, a sentence such as (ia) is to be represented by a pair of representations, as shown in (ib).

(i) a. Every farmer admires a widow.

b.

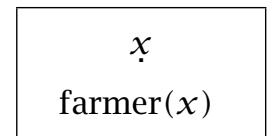

$\mathrm{K}_{1}$

\begin{tabular}{l}
\multicolumn{1}{c|}{$\quad y$} \\
farmer $(x)$ \\
$x$ admires a widow \\
widow $(y)$ \\
$x$ admires $y$
\end{tabular}

$\mathrm{K}_{2}$

According to the representation structure in (ib), (ia) is true in a model $\mathcal{M}$ (of the type discussed in section I) iff every proper embedding of $\mathrm{K}_{1}$ can be extended to a proper embedding of $\mathrm{K}_{2}$. A similarly constructed DRS for the proposition expressed by the sentence in (22b) would have the form given in (ii).

(ii)

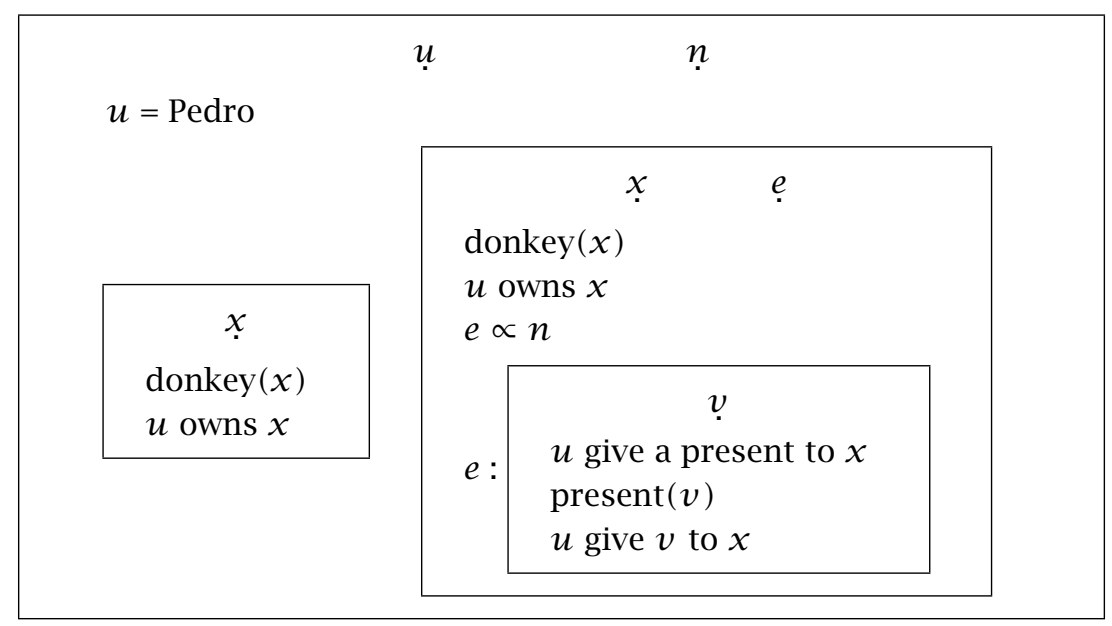

The truth conditions conveyed by this DRS are, informally stated, that there is individual Pedro such that for each one of that individual's donkeys there occurred an event, before the utterance time represented by $n$, of him giving at least one present to that donkey. 
This, however, is a solution which, even if it is acceptable for (22b), will not work in general. Consider for instance the sentence in (26).

The children were attacked by wolves.

This sentence is certainly true on an occasion where each of the children is attacked by at least one wolf. But surely this condition is not necessary. Example (26) would still be true if one or two members of the group of children escaped personal attack, as long as a substantial part of the group did not; it is, one feels, naturally interpreted as reporting one single event, an attack on a group of children by a group of wolves. This event will in some cases be just the "sum" of events every one of which is an attack of a single individual. But in general there need not be such a component event for each of the individuals that belong to the set mentioned in the specification of the sum event; and sometimes - viz., where, as we say, the children were attacked "collectively", or "as a group" - there may not even be a natural way of separating out any such component event at all.

It might be urged that this last problem is not specifically a problem about events, or about the analysis of sentences reporting them, but more generally about the relation between plural and singular. Plural sentences can sometimes be paraphrased in a language which admits only the singular and which renders the effect of plural terms with the help of determiners such as every and $a$. But usually such paraphrases are not to be had and the plural sentence must be analyzed as involving irreducible properties or relations that are predicated of the denotations of the plural terms it contains.

But if it is conceded that the problem is not specific to event descriptions, it nonetheless remains true that it does arise also in connection with them, and this suffices for the point that should be made here. The point I am concerned to make is that while there exists some more or less systematic connection between the truth conditions of, say, (26) and sentences of the form (27), it is apparently impossible to state this connection uniformly in comparatively simple terms; in particular, I can see no way of describing in a generally accurate manner how the truth conditions of sentences of the type (27) determine the truth conditions of a sentence such as (26):

(27) $x$ was attacked by $y$

where $x$ and $y$ each stand for a single individual, such as a person or an animal. 
Events, discourse representations and temporal reference

We find ourselves here at the limes of that model-theoretic program which attempts to reduce the truth conditions of all sentences of the language to those for a comparatively small number of "primitive" expressions. In the case of plurals, for instance, the best that we can hope for is something considerably less ambitious than that which this program suggests: we must treat plural forms of verbs as primitive verbs in their own right, and state, as well as we can, how their satisfaction conditions link up with the satisfaction conditions for the corresponding singular verbs. ${ }^{14}$ These correlations will act as constraints on the possible models for fragments containing both plurals and singulars in which certain verbs are assigned extensions involving sets of individuals and other related verbs (extensions) involving particular individuals belonging to these sets. (One typical form for such a correlation principle would be that a set cannot belong to the extension of the first verb unless certain members of it belong to the extension of the second.) The irreducibility of plural to singular will manifest itself both at the level of representation and in relation to the models. Thus the DRS of (27) will be of some such form as that shown in (28).

14 Actually this is not entirely accurate, in so far as the singular verb form is itself sometimes used in that sense which is here being attributed to the plural, viz., that where the subject term denotes a collection of individuals each of which is a possible relatum for the singular verb in its "primary" sense (of which the present discussion might be taken to imply that it would be its only sense). Of course, singular terms can also denote such collections - compare for instance (ia) with the virtually synonymous (ib).

(i) a. The children were attacked by wolves.

b. The group of children was attacked by wolves.

Moreover, the morphological distinction between plural and singular verb forms is relevant only in relation to the syntactic subject - at least this is so in languages such as English and French - with which the verb form is linked by obligatory number agreement; but of course the very same distinction that we have been drawing here needs to be made also with regard to other argument positions, such as that of a direct object. However, as there is no room in this paper for formal treatment of these various verb senses anyway, no harm will come from the oversimplified form in which I have treated this matter here. 
Hans Kamp

(28)

e $\quad$ n $\quad$ u
$e \propto n$
$e: \begin{aligned} & \text { The children be attacked by wolves } \\ & u \text { be attacked by wolves } \\ & u \text { be attacked by } v\end{aligned}$
$\begin{aligned} & u=\text { the children } \\ & \text { wolves }(v)\end{aligned}$

Here $u$ and $v$ are discourse sets, representing the set of children and some set of wolves. It is tempting, but not always warranted, to extend this DRS by introducing further events specified as attacks of individual children, or attacks by individual wolves.

A model $\mathcal{M}$ in which this DRS can be properly embedded must contain an event $e^{\prime}$ which is specified by $\mathcal{M}$ as an attack of one group by another group; and again no reduction of this specification to data involving individual members of those groups seems possible in general.

We have encountered two kinds of difficulty which arise in the analysis and interpretation of the nontemporal specifications of events. As I have already said, neither of these particular difficulties manifests itself within the fragment considered here, as that does not contain either adverbs or plurals. But a difficulty akin to the second of these arises in connection with certain constructions whose analysis is an essential part of this paper's purpose. As has been repeatedly observed in the existing literature, there is a problem about stating the truth conditions of English sentences which contain progressive forms of certain verb phrases. ${ }^{15}$ Thus (29) may be true even if Chiquita's kick left Pedro dead and, consequently, prevented the completion of the stable.

(29) Pedro was building a stable when Chiquita kicked him.

In fact, there may not even have existed at the time of the kicking anything, no matter how unfinished, that could be called a stable. Example (29) would be true in such a situation so long as Pedro was engaged in the activity of building a stable, even though the action of building a stable was never brought to a successful conclusion. It is to be contrasted with sentences such

15 See in particular Dowty 1979. 
Events, discourse representations and temporal reference

as (30a)-(3ob), which are true only if the reported activity actually did issue in an essentially completed edifice.

(30) a. Pedro has built a stable.

b. Last year Pedro built a stable.

Dowty (1979) proposes a formula which reduces the truth conditions of clauses such as Pedro was building a stable to those of clauses such as Pedro built a stable. He suggests (roughly) that (29) is true with respect to an interval $i$ in a world $w$ iff in certain plausible but not necessarily actual future continuations of $w$ after $i, i$ is an initial segment of an interval $i^{\prime}$ in which the building completed. But as Dowty himself observes, one hesitates to feel fully satisfied with this proposal as it stands, since it is difficult to see how precisely the relevant set of "plausible" continuations of $w$ after $i$ should be defined or, for that matter, conceived. Indeed, it seems very doubtful that such a definition could actually be found. Nor will it do to treat the progressive form of the verb as semantically basic and to try and characterize the truth conditions of sentences such as (30a) and (3ob) in terms of sentences such as (29). For intuitively this is going the wrong way round: it would appear that we have a basic understanding of what it is to build a particular building, from which our understanding of what it is to be engaged in the activity of building is derivative; an analysis which treats progressive forms as more fundamental than their nonprogressive counterparts goes straight against this intuition. The remaining option is, once again, the least attractive one from a traditional methodological standpoint, but it appears to be the only feasible one: our models are to provide separate extensions for progressive and nonprogressive forms of the same verbs, while correlation principles are to ensure that these extensions mesh with each other.

The contrast between the English past progressive and simple past is matched in many ways by that between imparfait and passé simple in French. Indeed the particular problem which we just discussed must be faced also in connection with the two past tenses of French which have been among our primary concerns in this paper. Compare for instance (10) with (11). The imparfait Marie faisait la vaisselle of (10) conveys, I argued earlier, that Marie was engaged in the activity of doing the dishes at the time when Pierre entered the kitchen. Nothing was asserted by that sentence concerning whether that activity was to outlast the event of Pierre's entering the kitchen with which it was presented as temporally overlapping. We may add to that observation now that it is not decided either by the imparfait sentence 
whether Marie ever finished doing the dishes (whether at or after the time of Pierre's entry). In this regard the imparfait of (11) must clearly be contrasted with the sentence Marie a fait la vaisselle of (10), which does imply that the process was completed.

Two conclusions emerge from these considerations. The first is that we require for many verbs two extensions rather than one; the second that while there exist certain more or less systematic connections between these extensions, it is beyond our present capacity to state exactly what these connections are.

We already decided how to encode those extensions of English nonstative verbs which are needed for the evaluation of their simple past forms, and, by the same token, the extensions of French verbs that yield the evaluations of their occurrences in the passé simple. These are to be given as sets of tuples involving events and possibly one or more other individuals. How should the other extension - that necessary for the evaluation of the French imparfait and, in English, the progressive - be encoded? Our treatment in (13) of the clause Marie faisait la vaisselle involved the introduction of a discourse state $s$. This implies that a model into which (13) can be properly embedded must contain a state $s^{\prime}$ onto which this $s$ can be mapped. But what are states? Our intuitions about states are less clear, it seems to me, than our intuitions about events, and various accounts appear to be consistent with what is predetermined by our pretheoretical conceptual apparatus. The following account will do as well as any of its alternatives: each state of a given interval model $\mathcal{M}$ is identifiable in terms of (i) an interval $i$ of $\mathcal{T}_{\mathcal{M}}$ and (ii) a certain set of conditions which hold during $i$ in $\mathcal{M} .{ }^{16}$ The problem here is to determine what the sets of conditions are that identify states. This problem is essentially of the same sort as the one we encountered when trying to determine which conditions are directly involved in the verification of event specifications.

We noted in connection with the earlier question that most of the real difficulties do not arise within the quite limited language fragment considered in this paper (as defined in the appendix), and this is equally true of the present one about states. There is one problem, however, which does arise for us and it is high time that we should address ourselves to it. This is the problem, already raised in connection with the question of how to verify

16 We could define the states of $\mathcal{M}$ to be pairs consisting of an interval together with such a set of conditions obtaining during the interval; but nothing much will be gained from such a reduction; it suffices if we postulate that for each such pair there is one and only one state which that pair identifies. 
Events, discourse representations and temporal reference

the specifications of events, what types of verbs the relevant conditions may contain. From what has already been said it should be clear that the answers to the two parallel questions - viz., the one concerning the identification of states and the one which concerns the identification of events - must be complimentary: verbs that are relevant in connection with events are eo ipso not to be used for the identification of states. The distinction we need here is essentially that between stative and nonstative verbs. ${ }^{17}$ Stative verbs such as own or admire can only be used for the identification of states. So called nonstative verbs, on the other hand, e.g., build in build a stable, admit a stative as well as a nonstative form. In fact, there are various ways of forming stative verb phrases out of verbs which must count as nonstative according to Vendler's classification. In English the progressive is one of these; the present perfect is another. ${ }^{18} \mathrm{~A}$ third way of turning a nonstative English verb into a stative verb consists in assigning to it a habitual, frequentative or dispositional sense - as we are inclined to do for instance to the verb beat in (1a).

Of these three ways in which nonstatives can be transformed into statives, only the progressive is of concern to us here. It is of concern to us, moreover, primarily because of the similarities between the role of the past progressive and the imparfait in French. (In fact it was because of this similarity that I brought up the progressive in the first place.) There are however certain differences between the functions of the English simple past and the past progressive on the one hand and those of the French passé simple and imparfait on the other. The distinction between stative and nonstative verbs in English is often motivated by the observation that certain verb phrases, viz., the so-called "stative" ones, do not admit progressive forms. Indeed, inadmissibility of the progressive is one of the main criteria for distinguishing English statives from nonstatives. ${ }^{19}$ To put the matter somewhat differently and in a manner more commensurate with the perspective of the present essay, English stative verbs are distinguished from nonstatives in that they only admit a stative interpretation. (It is because they are statives already anyway that the progressive is otiose when applied to them, and this I take

17 Cf., e.g., Vendler 1957 for such a classification of verbs. An excellent discussion of these matters can be found in Dowty 1979.

18 In fact, there are various other grammatical constructions which form verbs of one aspectual type out of verbs belonging to another, a phenomenon that has been studied in considerable detail in for instance Verkuyl 1972 and Dowty 1979.

19 Cf. Vendler 1957. 
it must be the reason why the progressive forms of such verbs are judged as deviant.) French does not possess the progressive, so that the mentioned criterion for distinguishing statives from nonstatives is not available there (although we can devise a similar one with the help of the control verb etre en train de). ${ }^{20}$ But in view of the principle that the imparfait conveys stativity whereas the passé simple signifies its opposite we might expect that a similar distinction may be drawn between those French verbs which can occur in the passé simple as well as the imparfait and those which can occur in the imparfait only. However, verbs of the latter kind appear to be nonexistent - although it should be said that often when the French counterpart of a paradigmatically stative English verb occurs in the passé simple it must be given an inchoative reading (as in il sut la réponse, il fut President).

I cannot see therefore how we could, in a way relevant to our present problems of analysis, distinguish between French verbs that can be used to identify events as well as states, and those which identify states only. Rather it seems that every verb can serve either purpose when placed in the right context. ${ }^{21}$

\section{Conclusions}

Let us recapitulate to see where all this leaves us with regard to the question which gave the impetus to the inquiry of the preceding pages - the question what form we should adopt for the models in which DRSs such as (12) and (13) can be interpreted. We already committed ourselves to a temporal component comprising both times and events. We also stipulated that the events are to receive their temporal specifications via their part in the extensions of nonstative verbs, and that these extensions are to consist of tuples consisting

20 Cf. Nef 1980: 17-19

21 We cannot fail to ask the very same question at this point about English: can typically stative verbs of English not also be used to report events? Almost certainly the answer should be the same here as for French - we can say, for instance, and then I knew the answer, suggesting the very same inchoative interpretation that is carried by the passé simple of the French savoir. The question is ultimately whether we should postulate for such English stative verbs as know also two extensions, one reflecting the genuinely stative reading of the verb and the other the inchoative reading, on which the verb expresses a transition from absence to presence of the state it represents on the first reading; or whether the first of these two readings will be enough, the second being derivable from it by a completely systematic procedure. I do not quite see how to answer this question at the moment. 
Events, discourse representations and temporal reference

of events and possibly other objects. We have not yet decided how we should represent the extensions for stative (readings of) verbs. These extensions are best given, it seems to me, in the form which was proposed earlier in connection with interval models, i.e., as functions which assign to intervals pairs of disjoint sets consisting either of single individuals or of tuples of individuals. Similarly, we shall stick to the earlier proposal to represent the extensions of nouns by functions from intervals to pairs of disjoint sets of individuals, and to assign single individuals to names.

What remains to be decided is how precisely we are to deal with states. But in view of our earlier informal remarks there would seem to be in essence only one way of introducing them: we add to the model $\mathcal{M}$ - and let us assume, although nothing hangs on this, to its temporal component $-\mathrm{a}$ set $S$ of states, and moreover a function $\mathscr{S}$ which establishes a one-to-one correspondence between the members of $S$ and the state-identifying pairs of $\mathcal{M}$, i.e., between $S$ and the set of all pairs $\langle i, \Gamma\rangle$ where $i$ is an interval of $\mathcal{M}$ and $\Gamma$ is a collection of sequences, each consisting of a condition and a suitable number of objects from $\mathcal{M}$ which satisfy that condition during $i$. The function $\mathscr{S}$ evidently determines the nontemporal specifications of the states, so that there is no need to add a further component which provides such information. Similarly the temporal relations between states and other temporal entities are fully determined by the temporal relations that are entered into by the corresponding intervals. ${ }^{22}$

If these are the various components which constitute the model, then what are the systematic relations which connect these components? We have already stated the principle which links events and times (cf. section III). And we have noted how very difficult it is to find generally valid correlation principles that link the existence of events with that of states. In fact, there is only one principle that I can think of in this connection which appears to be generally correct:

(31) Whenever the extension of the nonstative verb $\alpha$ contains the tuple $\left\langle e, a_{1}, \ldots, a_{n}\right\rangle$, there is a state $s$ such that if $\mathscr{S}(s)=\langle i, \Gamma\rangle$, then $\Gamma$ contains the tuple $\left\langle\alpha^{\prime}, a_{1}, \ldots, a_{n}\right\rangle$, where $\alpha^{\prime}$ is the stative version of $\alpha .^{23}$

22 [There is a conflict between the function $\mathscr{S}$ spoken of here and a function bearing the same name that is part of the definition of the model $\mathcal{M}$ in part III of the appendix. See footnote 37 on page 57 for a discussion of this conflict. - HK, 2016] 
But this relation does not appear to be always the same. We must distinguish here between, on the one hand, accomplishment and activity verbs and, on the other, achievement verbs. ${ }^{24}$ If $e$ is an event of $x$ 's satisfying an accomplishment or activity verb, the state that $x$ is in in virtue of being thus engaged is always temporally included in $e$. But if $e$ is the event of satisfying an achievement verb the state typically occupies a period just preceding $e$. (Compare: Pedro was building a stable with Chiquita was winning the race.) Thus, unless we are prepared to go into a more detailed classification of verbs than the simple distinction between statives and nonstatives provides we can say no more about the state guaranteed by an event $e$ than that it is either included in $e$ or else immediately precedes it.

A few pages earlier I claimed that our intuitions about states are quite indeterminate and that a number of specific proposals for identification of the set of states are equally consistent with what little is fixed by these intuitions. I then went on to make a particular proposal (which is the one I have in fact adopted in the formal definition of a model in the appendix), while implying that not much hangs on what particular proposal is selected, as long as it does not violate the preexisting intuitions in the few places where those are clear.

One might object against this that if there is no objective fact of the matter precisely what states there are but only certain constraints on what the set of states could be, and that if states are nonetheless essential to the evaluation of certain sentences, then the values which the evaluation process yields for these sentences ought to be independent from any features that distinguish one particular identification proposal from others. In relation to a given situation of speech we should therefore suppose not that there is a single model which reflects that situation, but rather that the reflecting model could be any one of a class, the members of which may differ in respect of what states they contain. Only when a sentence or discourse comes out true (or false) in each one of the models in the class can it be regarded as definitely true (or false) in the speech situation in question. ${ }^{25}$ Having raised this matter

23 That is, in English $\alpha^{\prime}$ would be the progressive form of $\alpha$; in French there will be no morphological distinction between $\alpha$ and $\alpha^{\prime}$.

$24 \mathrm{Cf}$. Vendler 1957. A typical instance of the category of accomplishment "verbs" is build a stable; an activity verb would be walk; and win the race is an example of an achievement verb.

25 The evaluation method according to which an expression has a definite value only if it has that value in each member of a given class of models is known as the supervaluation method. Cf. van Fraassen 1969, Fine 1975, Kamp 1975. 
Events, discourse representations and temporal reference

in connection with states we can hardly forestall a similar query about events. I said earlier that our intuitions about events are more determinate than those about states. But that does not mean that our intuitions settle what is, or is to count as an event completely. If indeed they do not, then the models corresponding to a given speech situation should be allowed to vary not only in respect of their states but also as regards their events. To work out the details of a semantic theory of this sort for the temporal constructions here considered is a far from trivial matter, however, and so I have decided not to pursue this line of inquiry any further here.

This is as far as I intend to go in this essay. Evidently very, very little has been accomplished of all that is required of an adequate semantic description of tensed discourse. Even so I hope to have given some idea in these pages of what can be accomplished in this area with the help of model-theoretic techniques, and also that the reader may have formed some appreciation of the indispensability of a separate level of discourse representation to any comprehensive account of the use and function of temporal expressions - even if the introduction of such a level is, as we have seen in this last section, by itself no cure for all the disabilities of the traditional model-theoretic approach that come to light once we attend more closely to the intricacies of tenses and all the other devices of temporal reference with which they interact.

\section{Preface to the appendix, 2016}

The appendix is the least successful part of this paper and also the part that is the most difficult to read. There are a number of things to it that I would now want to formulate differently (and quite a few of them have been formulated differently in work I have taken part in).

Reformulating things in keeping with later insights would have perverted the main point of this publication. But a few remarks on the motivations behind what follows below - whatever their merit - may help to put those who want to have a serious look at the appendix on the right track. The first and I suspect main source of possible confusion has to do with the characterization of the "events" and the "states" of the model $\mathcal{M}$ defined on page 55. There is a general problem here - one that confronts anybody trying to develop a theory of tense and aspect for a language like French - which has to do with two aspectual oppositions, at two different stages of the computation of the aspectual properties of complete sentences. On the 
one hand there is, in French, the impact of the tenses passé simple and imparfait. The paper treats the difference between these tense forms as the difference between events and states, a terminology which is not without its problems, but one that has persisted to this day. On the other hand there are the aspectual distinctions that are found at the lexical level: ever since Vendler 1957 we distinguish between "state verbs" and (various types of) "event verbs". And even in the tiny verb vocabulary of our fragment $L$ this difference is manifest: the transitive verbs construire, entrer dans, nettoyer are, by general reckoning, event verbs and posséder, aimer, admirer are state verbs. In the course of the past two or three decades the problem of how the aspectual properties of complete sentences are connected with the lexical properties of the verbs they contain has come into ever sharper focus and a great deal of effort has been and is being made to understand the different principles and mechanisms by which they are connected. (There appear to be significant differences on this point even between languages with tense systems that are by and large quite similar, which makes this a particularly challenging research issue.)

When I wrote "Events, discourse representations and temporal reference", my concern was with the difference between the aspectual roles played by passé simple and imparfait and I used the simplest way I could think of to capture that difference, by assuming that passé simple sentences always introduce an event into the discourse representation and imparfait sentences always a state. Thus it is discourse referents for these events and states that are found in the universes of the DRSs for which a model theory has to be provided. And since verification of a DRS in a model involves mapping its discourse entities to real entities of the same ontological sorts in the verifying (or falsifying) model, the models must contain events and states as well. But if those events and states are to be suited as mapping targets for the discourse events and discourse states that occur in the DRSs of this paper, then they too must be the kinds of events and states that passé simple and imparfait sentences can be seen to talk about, and to do that, partly, on account of their respective tenses.

There has been little about lexical aspect in this paper, and less than I would now think adequate. There have been some remarks on aspectual distinctions between individual verbs on pages 38 and 42), but these play little role in the formalization presented in the appendix beyond motivating the proposed relation between events and states which is defined in clause (xi) in the definition of models. The semantics of lexical verbs is represented (in a 
Events, discourse representations and temporal reference

model $\mathcal{M}$ ) as if they were one-place or two-place predicates, just as common nouns are treated as one-place predicates. All those words are assigned extensions in $\mathcal{M}$ for each time interval $i$, in the more or less traditional way according to which, say, the pair $\langle a, b\rangle$ belongs to the extension of the verb aimer at the interval $i$ iff, intuitively, $a$ loves $b$ throughout $i$. (This is done by the function $\mathscr{F}_{2}$; see clause (viii) in the definition of models. By the way, in this definition the extensions of predicate words are allowed to have gaps - hence the characterization of extensions as pairs consisting of a positive and a negative set - but this is a complication that in the end does no work given the simplicity of the fragment L and the DRSs it generates. For further remarks on the motivation for these gaps, see the postscript, page 64.)

Given that the extension of a verb $\mathrm{V}$ in $\mathcal{M}$ is specified to begin with in this manner, more needs to be said about how these extensions are related to the events and states that correspond to the discourse events and discourse states introduced by passé simple and imparfait sentences in which $\mathrm{V}$ is the main verb. This is implemented in different ways for events and states, ways that were intended to capture the intuition that events have an identity that is to some extent independent from the ways in which we describe them; for states, the intuition had it, this is not so - a state is fully identified by (i) the predication that we use to describe it and (ii) the period of time that it occupies.

In addition it is also necessary to articulate a connection between events and states. In the present setup that necessity arises because each verb can in principle give rise to both events and states, insofar as it can be the main verb of both passé simple and imparfait sentences. For each of these relations it is important to make sure that the times of the basic extensions of the verbs and the periods of time occupied by the events and states that can be described by sentences with that verb are correlated in the right way. In the version before you I have tried to make sure that these temporal locations of events, states and verb extensions are matched correctly. (Parts of the appendix were missing from the type script that was the principal source for the reconstruction of the English text presented here. For all I know there may have been some discrepancies between the English original and the version of the appendix that appeared in Langages. I have taken this element of uncertainty as a license to deviate from the French version in a few places where that version seemed to me to be obscured by what may have been either misprints or shortcomings to my own formulations in the 
original English manuscript.) The relevant clauses of the model definition on page 56 that deal with this three-way relation between traditional predicate extensions, events and states are (ix), (x) and (xi). Clause (ix) stipulates that the function $\mathscr{G}$ selects for each verb $\alpha$ the events in $\mathcal{M}$ that are described by $\alpha$ and its arguments, (x) articulates how the function $\mathscr{S}$ specifies the states that are described by a verb $\alpha$ and (xi) formulates some minimal connections between the states that are described by $\alpha$ and the events that $\alpha$ can be used to describe.

\section{Appendix}

This appendix contains a formal presentation of a fragment of French, ${ }^{26}$ which encompasses many, if not all, the types of discourse discussed in sections I-III. In what follows I have simplified certain matters; I start by listing these simplifications: ${ }^{27}$

i. I have omitted all temporal conjunctions.

ii. I have made the assumption that a sentence is formed by combining first the subject and the tenseless verb phrase into an infinitival clause, which is then transformed into the sentence by a second operation which imposes a finite tense form on the verb. This assumption, which I have adopted for reasons of simplicity, doesn't strike me as fully satisfactory; I would have preferred a single operation that combines tenseless verb phrases with subject and finite tense all at once in a single swoop. However, there are some problems with the implementation of this idea, which is why I have opted for the assumption I am making.

iii. I have set aside the complexities connected with definite descriptions and therefore excluded these from the fragment.

iv. Little attention is paid to relative clauses.

26 [For the method of giving a fragment of some given natural language, see Montague 1970a, 1970b, 1973. - FN, 1981]

27 [In a footnote that appears at this point in the Langages paper, Nef notes that it was necessary to abridge this part of the appendix for reasons of space. This part of the unabridged English original was among the missing pages discussed in the preface to the appendix and thus it remains abridged. $-\mathrm{HK}, 2016]$ 
Events, discourse representations and temporal reference

v. As regards certain syntactic features, such as, for instance, FEM (féminin), I have not bothered to specify explicitly in the syntactic rules how such features combine with other syntactic categories to form subcategories; but this is a routine task that is within the reach of anyone who is prepared to engage in it.

vi. I haven't made fully explicit the principles that determine the specification of states and events in the DRSs of tensed discourses.

\section{Fragment L}

I. Syntax ${ }^{28}$

$\begin{array}{lc}\text { I.1 Principal Category Symbols } \\ \text { Categories } & \text { Category Symbols } \\ \text { Term } & \mathrm{T} \\ \text { Common Noun } & \mathrm{CN} \\ \text { Intransitive Verb Phrase } & \mathrm{IV} \\ \text { Transitive Verb Phrase } & \mathrm{TV} \\ \text { Sentential Form } & \mathrm{SF} \\ \text { Sentence } & \mathrm{S} \\ \text { Relative Clause } & \mathrm{RC} \\ \text { I.2 Features } & \\ \text { MAS masculin } & \\ \text { FEM féminin } & \\ \text { PRES présent } & \\ \text { PS passé simple } & \\ \text { IMP imparfait } & \end{array}$

I.3 Category Symbols:

28 [In the original Langages paper a shortcut was attempted in the statement of the following syntactic rules, but with the unintended and unfortunate effect that it made some of the formation rules say something different from what they were meant to say. (Thanks to Justin Cope for pointing this out.) Since the syntax defined in this appendix only serves the purpose of specifying which expressions belong to the fragment and of providing the semantics with the syntactic structures it can use as inputs, documenting the mistake explicitly for posterity didn't seem useful or meaningful. So we have simply corrected this mistake (as well as a couple of additional misprints) without dwelling on the matter. The fragment defined here is the one originally intended and so are the syntactic structures assigned to its well-formed expressions. - HK, 2016] 
$\{\mathrm{T}, \mathrm{MAS}\},\{\mathrm{T}, \mathrm{FEM}\},\{\mathrm{CN}, \mathrm{MAS}\},\{\mathrm{CN}, \mathrm{FEM}\},\{\mathrm{RC}, \mathrm{MAS}\},\{\mathrm{RC}, \mathrm{FEM}\}$, $\{\mathrm{IV}\},\{\mathrm{TV}\},\{\mathrm{SF}\},\{\mathrm{S}, \mathrm{PRES}\},\{\mathrm{S}, \mathrm{PS}\},\{\mathrm{S}, \mathrm{IMP}\}$

Notation: If $\Gamma$ is a category symbol and $\alpha$ an expression, " $\alpha \in \Gamma$ ” says that $\alpha$ belongs to the category labeled by $\Gamma$.

I.4 Vocabulary

\{T, MAS\}: Pedro, Pierre, Jean, il

\{T, FEM\}: Chiquita, Marie, elle, l'étable, la salle de bains, la cuisine

\{CN, MAS\}: fermier, âne

$\{\mathrm{CN}, \mathrm{FEM}\}$ : maison, veuve

\{IV\}: faire la vaisselle

$\{\mathrm{TV}\}$ : construire, entrer dans, nettoyer, posséder, aimer, admirer

The vocabulary items are also referred to as the "primitive" members of their respective categories. Thus âne is a primitive $\{\mathrm{CN}, \mathrm{MAS}\}$ and nettoyer a primitive $\{\mathrm{TV}\}$.

\section{I.5 Formation Rules}

FR.1 i. If $\alpha \in\{\mathrm{CN}, \mathrm{MAS}\}$, then $u n \alpha \in\{\mathrm{T}, \mathrm{MAS}\}$;

ii. if $\alpha \in\{\mathrm{CN}, \mathrm{FEM}\}$, then une $\alpha \in\{\mathrm{T}, \mathrm{FEM}\}$.

FR.2 If $\alpha \in\{\mathrm{IV}\}$ and $\beta \in\{\mathrm{T}, \gamma\}$, where $\gamma=$ MAS or $\gamma=$ FEM, then $\beta \alpha \in\{\mathrm{SF}\}$.

FR.3 If $\alpha \in\{\mathrm{SF}\}$, then

i. $\alpha^{\prime} \in\{\mathrm{S}$, PRES $\}$, where $\alpha^{\prime}$ results from replacing the main verb of $\alpha$ by its third person singular present tense form; ${ }^{29}$

ii. $\alpha^{\prime \prime} \in\{\mathrm{S}, \mathrm{IMP}\}$, where $\alpha^{\prime \prime}$ results from replacing the main verb of $\alpha$ by its third person singular imparfait form;

iii. $\alpha^{\prime \prime \prime} \in\{\mathrm{S}, \mathrm{PS}\}$, where $\alpha^{\prime \prime \prime}$ results from replacing the main verb of $\alpha$ by its third person singular passé simple form.

FR.4 If $\alpha \in\{\mathrm{TV}\}$ and $\beta \in\{\mathrm{T}, \gamma\}$, where $\gamma=$ MAS or $\gamma=$ FEM, then $\delta \in\{$ IV $\}$, where

i. if $\beta=i l$ and $\alpha$ ends with a preposition, then $\delta=\alpha$ lui;

29 Strictly speaking the relation " $\beta$ is the main verb of $\alpha$ " should be explicitly defined in simultaneous recursion with the categories themselves: but as it is obvious how this can be done, I have decided to omit this. 
Events, discourse representations and temporal reference

ii. if $\beta=$ il and $\alpha$ does not end with a preposition, then $\delta=l ' \alpha$ or $\delta=$ le $\alpha$, depending on whether $\alpha$ does or does not begin with a vowel;

iii. if $\beta=$ elle and $\alpha$ ends with a preposition, then $\delta=\alpha$ elle;

iv. if $\beta=$ elle and $\alpha$ does not end with a preposition, then $\delta=$ l' $\alpha$ or $\delta=$ la $\alpha$, depending on whether $\alpha$ does or does not begin with a vowel;

v. if $\beta$ is not a pronoun, then $\delta=\alpha \beta$.

FR.5.k If $\phi \in\{\mathrm{S}, \gamma\}$, where $\gamma=$ PRES or $\gamma=$ PS or $\gamma=$ IMP, and the $k$-th word of $\phi$ is

i. il, then $\beta \phi^{\prime} \in\{\mathrm{RC}, \mathrm{MAS}\}$, where $\beta=q u i$ and $\phi^{\prime}$ is the result of omitting the $k$-th word from $\phi$;

ii. elle and is not immediately preceded by a preposition, then $\beta \phi^{\prime} \in\{\mathrm{RC}, \mathrm{FEM}\}$, where $\beta=q u i, \phi^{\prime}$ is as under (i);

iii. a masculine pronoun of the form l' or le, then $\beta \phi^{\prime} \in$ $\{\mathrm{RC}, \mathrm{MAS}\}$, where $\phi^{\prime}$ is as under (i) and $\beta=q u^{\prime}$ or $\beta=$ que depending on whether $\phi^{\prime}$ does or does not begin with a vowel;

iv. a feminine pronoun of the form l' or $l a$, then $\beta \phi^{\prime} \in$ $\{$ RC, FEM $\}$, where $\phi^{\prime}$ and $\beta$ are as under (iii);

v. lui and follows a preposition $\delta$, then $\beta \phi^{\prime} \in\{\mathrm{RC}, \mathrm{MAS}\}$, where $\phi^{\prime}$ is obtained by omitting both the $k$ th and the $(k-1)$ th word (i.e., the pronoun lui and the preposition $\delta$ preceding it) and $\beta=\delta$ qui;

vi. elle and is preceded by a preposition $\delta$, then $\beta \phi^{\prime} \in$ $\{$ RC, FEM $\}$, where $\phi^{\prime}$ and $\beta$ are as described under (v). ${ }^{30}$

FR.6 If $\alpha$ is a primitive member of $\{\mathrm{CN}, \gamma\}$ and $\beta \in\{\mathrm{RC}, \gamma\}$, where $\gamma=$ MAS or $\gamma=$ FEM, then $\alpha \beta \in\{\mathrm{CN}, \gamma\}$.

II. Discourses and Discourse Representations

The following will be a somewhat abridged, and, in certain respects, much simplified, adaptation to the requirements of the present fragment of the rigorous account that is offered in Kamp 1981a for an exclusively present tense fragment of English.

30 [This formation rule will not do for a discourse in which the antecedent of elle is inanimate (e.g., l'étable), and a similar caveat could have been made for (v) if $\mathrm{L}$ had allowed for inanimate masculine nouns. But I ignore this here. - HK, 2016] 


\section{II.1 Discourses}

By a discourse of the fragment $\mathrm{L}$ defined by the syntax above we understand any finite sequence of sentences of L. We only consider discourses $\mathrm{D}$ in which each complete sentence $S_{i}$ counts as a new assertion, which adds information to that conveyed by the preceding sentences of $\mathrm{D}$. If each of the sentences in $\mathrm{D}$ is in the present tense (i.e., belongs to the category $\{\mathrm{S}, \mathrm{PRES}\}$ ), D will be called a present tense discourse; and if each of its sentences belongs to either $\{\mathrm{S}, \mathrm{PS}\}$ or $\{\mathrm{S}, \mathrm{IMP}\}$, D is called a past tense discourse. We assume some standard procedure for identifying for any discourse $\mathrm{D}$, each of the expression occurrences in $\mathrm{D}$, so as to be able to distinguish the various different occurrences in $\mathrm{D}$ of one and the same expression.

\section{II.2 Discourse Representation Structures}

A Discourse Representation Structure (or "DRS") for a discourse D of L will consist of

i. a set of discourse referents. We may assume that these are drawn from four pairwise-disjoint fixed sets, the set $E_{\mathrm{R}}$ of discourse events, the set $S_{\mathrm{R}}$ of discourse states, the set $T_{\mathrm{R}}$ of discourse times (with a distinguished element $n$ ), and the set $U_{\mathrm{R}}$ of discourse individuals;

ii. a set of conditions. These fall into four types:

a. Conditions which can be obtained from sentences of $\mathrm{L}$ by replacing one or more singular terms by discourse referents. Among these are those of the form " $u \alpha$ ", where $u \in U_{\mathrm{R}}$ and $\alpha$ is a primitive $\{$ IV $\}$ and those of the form " $u \alpha v$ " where $u, v \in U_{\mathrm{R}}$ and $\alpha$ is a primitive $\{\mathrm{TV}\}$. These are the irreducible conditions of type (a). Irreducible conditions play a special and crucial part in the model-theoretic semantics of DRSs. All the remaining conditions, of types (b)-(d) below, are irreducible.

b. Conditions of the form " $\alpha(u)$ ", where $u \in U_{\mathrm{R}}$ and $\alpha$ is a primitive common noun, and conditions of the form " $u=\beta$ ", where $u \in U_{\mathrm{R}}$ and $\beta$ is a proper name or definite description.

c. Conditions of the form " $\alpha \gamma \beta$ ", where $\alpha$ and $\beta$ are discourse events, states or times and $\gamma$ is some temporal 
Events, discourse representations and temporal reference

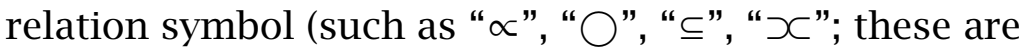
the only such relations considered here).

d. Conditions that are content specifications of states or events. These take the form of a discourse event or discourse state followed by a colon and a list of conditions of types (a) and (b). (In principle there is the possibility of recursion here, in that the conditions occurring within the content of a given discourse event or state could be or contain content specifications in their turn. But in the present fragment that possibility is ignored in order to keep matters reasonably simple).

\section{II.3 DRS Construction}

Let $\mathrm{D}=\left\langle\mathrm{S}_{1}, \ldots, \mathrm{S}_{n}\right\rangle$ be a discourse of L. A DRS for D is constructed by reducing the sentences $S_{1}, \ldots, S_{n}$ in the order in which they occur in D. The reduction of a sentence $S_{i}$ proceeds through the application of certain DRS-construction rules, which operate on the syntactic analysis of $S_{i}$ and work "from the top down", so to speak. (The syntactic analysis of $S_{i}$, according to the syntax defined under part I, imposes a partial order on how the rules are to be applied; for details on this, see once again Kamp 1981a.) What DRS-construction rule is to be applied at any given point of the DRS construction depends on the particular syntactic formation rule that was used to form the syntactic compound that is to be reduced by the application of the construction rule. In those cases where one of the immediate components of the compound is a singular term, moreover, the choice of construction rule will be determined by the form of this term; thus, for instance, there are different rules for proper names, indefinite descriptions and pronouns, respectively. Similarly, there are different rules for each of the tenses included in the fragment.

The reduction of compound sentences will as a rule yield conditions of type (a) which are themselves composite and need to be reduced further. Since such a condition, if it is not a sentence of L itself, always comes from an L-sentence via substitution of discourse referents for terms, the syntactic analysis of the original sentence of $L$ induces a syntactic decomposition of the condition and this decomposition constrains the order of rule 
applications to the reduction products of the condition in the manner indicated.

\section{II.4 Construction rules}

We describe the effect of each of these rules when it is applied to a sentence or condition of type (a) in an already partially constructed DRS K. This effect always takes the form of adding to $\mathrm{K}$ further conditions and, sometimes, new discourse referents. Here are the various rules. The first three concern those cases where the compound expression occurrence $\phi$ that is to be reduced was formed by combining a singular term occurrence $\alpha$ with some other expression. (In the present fragment there are only two such modes of combination, viz., forming a sentential form out of a term and an $\{$ IV $\}$ and forming an $\{$ IV $\}$ out of a term and a $\{\mathrm{TV}\}$.)

CR.1 Suppose $\alpha$ is a proper name occurrence. Then we introduce a new discourse individual $u$ into the universe of $\mathrm{K}$, add " $u=\alpha$ " to the set of conditions of $\mathrm{K}$ and add below $\phi$ the condition $\phi^{\prime}$ that is obtained by substituting $u$ for $\alpha$ in $\phi .^{31}$

CR.2 Suppose $\alpha$ is an indefinite description, i.e., $\alpha$ is of the form un $\beta$ or une $\beta$.

i. First suppose $\beta$ is a basic common noun. Then we add a new discourse individual $u$ to the universe of $\mathrm{K}$, add to the set of its conditions $\beta(u)$ and add below $\phi$ the condition $\phi^{\prime}$ described in the statement of CR.1;

ii. Next, suppose that $\beta$ is of the form $\gamma \delta$, where $\gamma$ is a primitive common noun and $\delta$ a relative clause. Then we make the same additions as under (i) and add moreover to the set of conditions of $\mathrm{K}$ the condition $\delta^{\prime}$ which is obtained by substituting $u$ in the sentence $\zeta$ from which $\delta$ was obtained through application of the rule FR.5 for the pronoun which was eliminated from that sentence in the transition from $\zeta$ to $\delta$.

31 Here, as well as in the formulation of the remaining construction rules the phrase add below $\phi$ is to mean that if $\phi$ is part of the specification of a certain event or state then so is the condition added. Where the phrase below $\phi$ is not used, the condition added counts as not part of any event- or state-specification, even if the condition that is being reduced is part of such a specification. In such cases, the new condition is added as a new member of the condition set of $\mathrm{K}$. 
Events, discourse representations and temporal reference

CR.3 $\alpha$ is a pronoun. Then we choose a discourse individual $u$ that is already in the DRS, and add below $\phi$ the result $\phi^{\prime}$ of replacing $\alpha$ in $\phi$ by $u$.

The next rules apply in cases where the condition in question is a sentence $\gamma$ obtained from an underlying sentential form $\delta$ through putting a tense into its main verb.

CR.4 $\gamma$ is in the present tense. Then we add to the universe of $\mathrm{K} \mathrm{a}$ new discourse state $s$ as well as the distinguished discourse time $n$ (in case $n$ hasn't been introduced already). We add to the set of conditions of $\mathrm{K}$ the condition " $n \subseteq s$ " as well as the specification " $s: \delta$ ".

CR.5 $\gamma$ is in the passé simple. Then:

(i) We introduce into the universe of $\mathrm{K}$ a new discourse event $e$, as well as $n$ if it hasn't been introduced yet, and add to the set of conditions the conditions " $e \propto n$ " and "e $: \delta$ ".

(ii) Moreover, if some sentence $S_{i}$ of $\mathrm{D}$ belonging to $\{\mathrm{S}, \mathrm{PS}\}$ has already been reduced in the construction of $\mathrm{K}$, then

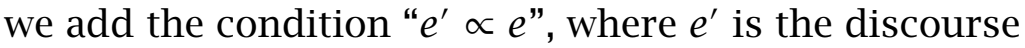
event that has been introduced in the last sentence of $\mathrm{D}$ belonging to $\{\mathrm{S}, \mathrm{PS}\}$ that precedes $\gamma$. Otherwise, if there are sentences from the category $\{\mathrm{S}, \mathrm{IMP}\}$ that precede in $\mathrm{D}$ the sentence that is currently being processed, then we add the condition " $e \subseteq s^{\prime}$ ", where $s$ ' is the discourse state introduced by the last preceding $\{\mathrm{S}, \mathrm{IMP}\}$ sentence.

CR.6 $\gamma$ is in the imparfait. Then:

(i) We introduce into the universe of $\mathrm{K}$ a new discourse state $s$ and we add to the set of conditions " $s \propto n$ " and " $s: \delta$ ". 32

(ii) Provided there is a sentence $S_{i}$ as described under CR.5, then we add the condition " $e$ ' $\subseteq s$ " where $e^{\prime}$ is the dis-

32 [This rule seems to contradict the remark on page 26 on the difference between the passé simple and imparfait, where it is noted that while the passé simple locates the described event squarely in the past, the imparfait does not impose such a restriction on the state described by its clause. The contradiction is only apparent, however. The discourse referents introduced by a sentence in the imparfait can denote what is intuitively a state that is part of some more exhaustive state and the part may be confined to the past even when the larger state overlaps with the utterance time. - HK, 2016] 
course event introduced in the reduction of the last sentence of that type. Otherwise, if there are sentences from the category $\{\mathrm{S}, \mathrm{IMP}\}$ that precede in $\mathrm{D}$ the sentence that is currently being processed, then we add the condition " $s \bigcirc s^{\prime}$ ", where $s^{\prime}$ is the discourse state introduced by the last preceding $\{\mathrm{S}$, IMP $\}$ sentence.

I have split CR.5 and CR.6 into two parts. The reason for this is that while the additions demanded by the first parts are indubitably correct, those demanded by the second are much more problematic. In fact it is not hard to find counterexamples to the second parts of both CR.5 and CR.6. Thus there are sequences of passé simple sentences which do not have to be interpreted as referring to consecutive events. Example (21), repeated below as (32), is an example of this sort:

(32) Cet été-là voyait plusieurs changements dans l'existence de nos héros. Paul épousa Francine; Jean-Louis partit pour l'Afrique et Pedro s'acheta un âne.

'That summer saw several changes in the life of our heroes. Paul married Francine, Jean-Louis set off for Africa and Pedro bought himself a donkey.'

The pressure to interpret the reported events as having occurred in an order which is homomorphic to that of the reporting sentences is typically absent or weak when the grammatical subjects of the successive sentences denote distinct individuals.

The second part of CR.6 is in conflict with examples such as this one:

(33) Jean ouvrit la porte. Il ne put rien voir mais il réussit a trouver l'interrupteur à tâtons. La lumière éclatante l'éblouissait.

'Jean opened the door. He couldn't see anything, but managed to find the switch. The brilliant light blinded him.'

Here the last sentence reports the state of affairs which resulted from Jean's finding the light switch (and presumably his then 
Events, discourse representations and temporal reference

turning the switch) and this state must have been subsequent to the event of his finding it. ${ }^{33}$

It is no simple matter, and one which is bound to involve many semantic factors upon which we haven't even touched here, to refine CR.5 and CR.6 in such a way that their second parts are applied in just the right cases. Here, as in so many other places where we have left problems unresolved, there is considerable scope for further work.

III. Models

We have already described our models in considerable detail in earlier sections. So the following definition will need no further elucidation.

By a model for L we understand a structure

$$
\mathcal{M}=\left\langle\mathcal{E}, \mathcal{T}, \mathscr{D}, \mathscr{U}, \mathscr{F}_{1}, \mathscr{F}_{2}, \mathscr{G}, \mathscr{S}\right\rangle
$$

where:

i. $\mathcal{E}$ is a triple $\langle E V, \propto, \bigcirc\rangle$ such that ${ }^{34}$

a. $E V=E \cup S$; $E$ and $S$ are the set of events of $\mathcal{E}$ and the set of states of $\mathcal{E}$.

b. $\propto$ and $\bigcirc$ are binary relations on $E V$ satisfying the postulates given under (16) and repeated here:

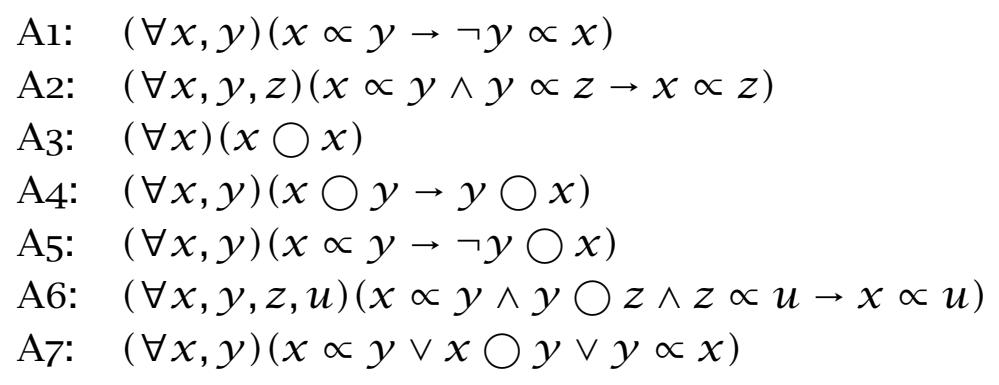

ii. $\mathcal{T}$ is a linear ordering $\langle T, \prec\rangle$. (T is called the set of instants of $\mathcal{M}$.)

33 This inadequacy of CR.6 has been observed in Hinrichs 1981.

34 [In the French translation, the relations $\propto$ and $\bigcirc$ in (i) and the function $\mathscr{D}$ in (iv) are defined only over $E$. States are independently correllated with intervals by $\mathscr{S}$ in (x). However, including the set of states in the temporal component of $\mathcal{M}$, as suggested in the conclusion of the main text (page 41), and defining $\propto, \bigcirc$ and $\mathscr{D}$ to range over $E \cup S$ allows for a simplification in the defintion of verification for conditions involving a temporal relation symbol (see clause (vi) of that definition). - HK, 2016] 
iii. The sets $E, S, T$ and $I_{\mathcal{T}}$, the set of intervals of $\mathcal{T}$, are all disjoint from each other.

iv. $\mathscr{D}$ is a function from $E V$ into $I_{\mathcal{T}}$ such that if $e v_{1}, e v_{2} \in E V$, then $e v_{1} \propto e v_{2}$ iff $\mathscr{D}\left(e v_{1}\right) \propto_{\mathcal{T}} \mathscr{D}\left(e v_{2}\right)$ and $e v_{1} \bigcirc e v_{2}$ iff $\mathscr{D}\left(e v_{1}\right) \bigcirc_{\mathcal{T}}$ $\mathscr{D}\left(e v_{2}\right)$.

v. If $E^{\prime}$ is a maximal set of pairwise-overlapping members of $E$, then there is a $t \in T$ such that for each $e \in E^{\prime}, t \in \mathscr{D}(e) .^{35}$

vi. $\mathscr{U}$ is a function whose domain is $I_{\mathcal{T}}$ and whose values are sets. If $i_{1} \subseteq i_{2}$, then, $\mathscr{U}\left(i_{2}\right) \subseteq \mathscr{U}\left(i_{1}\right)$. Let $\bar{U}$ be the set-theoretic union of the range of $\mathscr{U}$.

vii. $\mathscr{F}_{1}$ is a function which assigns to each proper name of $\mathrm{L}$ a member of $\bar{U}$.

viii. $\mathscr{F}_{2}$ is a function whose domain consists of the union of the sets of primitive common nouns, of primitive intransitive verbs and of transitive verbs of $\mathrm{L}$, and which maps each primitive common noun or intransitive verb $\alpha$ of $L$ to a function $[\alpha]_{\mathcal{M}}$ from $I_{\mathcal{T}}$ into pairs of disjoint subsets of $\bar{U}$. And if $\alpha$ is a transitive verb of $\mathrm{L}$, then for each $i \in I_{\mathcal{T}},[\alpha]_{\mathcal{M}}(i)$ is a pair of disjoint sets of pairs $\langle a, b\rangle$ with $a, b \in \bar{U}$. Here too the values assigned to different intervals stand in an inclusion relation that is the inverse of the inclusion relation between the intervals. For instance if $\alpha$ is a primitive common noun or intransitive verb of L, then, if $i_{1} \subseteq i_{2}$, then $[\alpha]_{\mathcal{M}}\left(i_{2}\right) \subseteq[\alpha]_{\mathcal{M}}\left(i_{1}\right)$.

ix. $\mathscr{G}$ is a function which maps each primitive intransitive verb $\alpha$ of L to a subset of $E \otimes \bar{U}$ and each transitive verb $\beta$ of L to a subset of $E \otimes \bar{U} \otimes \bar{U} \cdot{ }^{36}$

x. $\mathscr{S}$ is a one-to-one function whose domain is a subset of $S$ and which maps each member of its domain either to a pair $\langle i,\langle\alpha, a\rangle\rangle$, where $i \in I_{\mathcal{T}}, \alpha$ is an intransitive verb of $\mathrm{L}$ and $a$ is an individual

35 [See the discussion of the Russell-Wiener construction of temporal instants as maximal sets of pairwise-overlapping events on pages 21-23. Further discussion on page 28 motivates the decision to treat time as primitive. - HK, 2016]

36 [As noted by Cope, there is (or ought to be) an intuitive correlation between $\mathscr{G}$ and the function $\mathscr{F}_{2}$ which the original specifications failed to make explicit: if $\langle e, a\rangle \in \mathscr{G}(\alpha)$, where $\alpha$ is an intransitive verb of $\mathrm{L}$, then $a$ belongs to the first member of $\left(\mathscr{F}_{2}(\alpha)\right)(\mathscr{D}(e))$. Likewise, if $\langle e, a, b\rangle \in \mathscr{G}(\beta)$, where $\beta$ is a transitive verb of $\mathrm{L}$, then $\langle a, b\rangle$ belongs to the first member of $\left(\mathscr{F}_{2}(\beta)\right)(\mathscr{D}(e))$. - HK, 2016] 
Events, discourse representations and temporal reference

such that $a$ belongs to the first member of $[\alpha]_{\mathcal{M}}(i)$, or to a triple $\langle i,\langle\beta, a, b\rangle\rangle$, where $i$ is as above, $\beta$ is a transitive verb of $\mathrm{L}$ and $a$ and $b$ are individuals such that $\langle a, b\rangle$ belongs to the first member of $[\beta]_{\mathcal{M}}(i) .^{37}$

xi. If $\alpha$ is an intransitive verb of $\mathrm{L}$ such that $\langle e, a\rangle$ is in $\mathscr{G}(\alpha)$, then there is an $s$ in the domain of $\mathscr{S}$ such that $\mathscr{S}(s)=\langle i,\langle\alpha, a\rangle\rangle$ with $i \subseteq \mathscr{D}(e)$ or $i \propto \mathscr{D}(e)$. Likewise, if $\beta$ is a transitive verb of $\mathrm{L}$ such that $\langle\beta, a, b\rangle$ is in $\mathscr{G}(\beta)$, then there is an $s$ in the domain of $\mathscr{S}$ such that $\mathscr{S}(s)=\langle i,\langle\beta, a, b\rangle\rangle$ with $i \subseteq \mathscr{D}(e)$ or $i \propto \mathscr{D}(e) .^{38}$

\section{Verification}

Let $\mathrm{K}$ be a DRS for a discourse $\mathrm{D}$ of L, let $\mathcal{M}$ be a model, let $i \in I_{\mathcal{T}}$ and let $f$ be a function from the universe of $\mathrm{K}$ into $\bar{U} \cup I_{\mathcal{T}_{\mathcal{M}}} \cup E V_{\mathcal{M}}$. Then $f$ verifies $K$ in $\mathcal{M}$ with respect to $i$ iff $f$ identifies the interval $i$ as the "now" (or "speech time") $n$ of the discourse D represented by K and the irreducible conditions of $\mathrm{K}$ are satisfied in $\mathcal{M}$ by the values that $f$ assigns to the discourse referents they contain. (Such a function $f$ is also called a verifying embedding, or proper embedding, of $\mathrm{K}$ in $\mathcal{M}$ with respect to $i$.) Formally, $f$ verifies $K$ in $\mathcal{M}$ with respect to $i$ iff the following are satisfied:

i. $f(n)=i$.

ii. If $\gamma$ is an irreducible condition of $\mathrm{K}$ of type (a) occurring in the specification of a discourse event $e$ and $\gamma$ is of the form " $u \alpha$ " where $u$ is a discourse individual and $\alpha$ is an intransitive verb

37 [As mentioned in footnote 22 of the conclusion of the main body of the paper, there is a conflict between the function $\mathscr{S}$ defined there and the function $\mathscr{S}$ defined here. To keep the two apart, I will refer in this footnote to the function of the conclusion as $\mathscr{S}_{1}$ and to that of the definition of $\mathcal{M}$ as $\mathscr{S}_{2}$. These are the differences between $\mathscr{S}_{1}$ and $\mathscr{S}_{2}$. The first is that $\mathscr{S}_{1}$ provides characterizations of all states. These characterizations embody the intuitive idea that the identity of any state $s$ is fully determined by (i) its duration and (ii) a set of conditions that make up the "substance" of $s$. On the other hand, $\mathscr{S}_{2}$ is defined only for a subset of the totality of all states - those states whose substance is characterized by a single condition, the predicate of which is given by a verb of L. Suppose that the substance of $s$ is characterized via $\mathscr{S}_{2}$ by an intransitive verb $\alpha$ and some individual $a$, i.e., that $\mathscr{S}_{2}(s)=\langle i,\langle\alpha, a\rangle\rangle$. Then the characterization of $s$ according to $\mathscr{S}_{1}$ would be the pair $\langle i,\{\langle\alpha, a\rangle\}\rangle$. That is, the identity of $s$ is given by the duration $i$ and the singleton set whose only member is the condition that $a$ satisfies the verb $\alpha$. $-\mathrm{HK}, 2016]$

38 [For the motivation behind the relations between $i$ and $\mathscr{D}(e)$ that are given here, see the conclusion of the body of the paper, page 42. - HK, 2016] 
of $\mathrm{L}$, then $\langle f(e), f(u)\rangle \in \mathscr{G}(\alpha)$. Likewise, if $\gamma$ is an irreducible condition of $\mathrm{K}$ of type (a) occurring in the specification of a discourse event $e$ and $\gamma$ is of the form " $u \beta v$ " where $u$ and $v$ are discourse individuals and $\beta$ is a transitive verb of $\mathrm{L}$, then $\langle f(e v), f(u), f(v)\rangle \in \mathscr{G}(\beta)$.

iii. If $\gamma$ is an irreducible condition of $\mathrm{K}$ of type (a) occurring in the specification of a discourse state $s$ and $\gamma$ is of the form " $u \alpha$ " where $u$ is a discourse individual and $\alpha$ is an intransitive verb of $\mathrm{L}$, then $\langle\alpha, f(u)\rangle$ belongs to the first member of $\mathscr{S}(f(s))$. Likewise, if $\gamma$ is of the form " $u \beta v$ " where $u$ and $v$ are discourse individuals and $\beta$ is a transitive verb of $\mathrm{L}$, then $\langle\beta, f(u), f(v)\rangle$ belongs to the first member of $\mathscr{S}(f(s))$.

iv. If $\gamma$ is a condition of $\mathrm{K}$ of the form " $u=\beta$ " where $\beta$ is a proper name of $\mathrm{L}$, then $f(u)=\mathscr{F}_{1}(\beta)$.

v. If $\gamma$ is a condition of $\mathrm{K}$ of the form " $\alpha(u)$ " where $\alpha$ is a primitive common noun of $\mathrm{L}$ and $u$ is a discourse individual, then $f(u)$ belongs to the first member of $[\alpha]_{\mathcal{M}}(i)$.

vi. If $\gamma$ is a condition involving one of the temporal relation symbols " $\propto$ ", " $\bigcirc$ ", " $\subseteq$ ", " $\subset$ ", then the $f$-values of the discourse referents of the condition must stand in the relation denoted by the relation symbol in $\mathcal{M}$. These relations are defined for the intervals in $I_{\mathcal{T}}$ on the basis of $\mathcal{M}$ 's time structure $\mathcal{T}$ - " $\propto$ " denotes the interval relation $\propto_{\mathcal{T}}$, etc. - and can then be extended to relations on the set $I_{\mathcal{T}} \cup E V$ via the function $\mathscr{D}$. Thus, for example, the relation $\propto_{\mathcal{M}}$ on $I_{\mathcal{T}} \cup E V$ holds between two members $u$ and $v$ of $I_{\mathcal{T}} \cup E V$ iff $\mathscr{D}^{\prime}(u) \propto_{\mathcal{T}} \mathscr{D}^{\prime}(v)$, where $\mathscr{D}^{\prime}(u)=\mathscr{D}(u)$ if $u \in E V$ and $\mathscr{D}^{\prime}(u)=u$ if $u \in I_{\mathcal{T}}$, and likewise for $v$.

To return to the verification of DRS conditions $\gamma$ of the kind under discussion, suppose that $\gamma$ is of the form " $u \propto v$ ". Then $f$ verifies $\gamma$ iff $f(u)$ stands in the relation $\propto_{\mathcal{M}}$ to $f(v)$. And likewise for the other purely temporal relations.

V. Truth

A discourse $\mathrm{D}$ is true in a model $\mathcal{M}$ at a time $i \in I_{\mathcal{I}_{\mathcal{M}}}$ relative to a $D R S$ $K$ for $D$ iff there is a verifying embedding of $\mathrm{K}$ in $\mathcal{M}$ with respect to $i$. 
Events, discourse representations and temporal reference

\section{Postscript, 2016}

As noted in the footnote attached to the title of the paper, a French translation of it appeared as Kamp 1981b. Making available a text that is almost thirty-five years old, and of which a published version exists and has been in existence all this time, is something that cries out for an explanation.

One reason for doing this, urged upon me by some colleagues, is that the paper might still be of some interest today, but that it is quite hard to find and that it would be inaccessible to a number of potentially interested readers even when they could manage to lay their hands on it because it is in French.

My own, and somewhat personal, reasons for putting the English original before a wider public today are in large part historical. I have submitted the present version for publication because I hope that this may help to straighten out a misunderstanding of which I have seen a growing number of signs as the years have gone by. The misunderstanding may have been fostered in part by a paper by Barbara Partee, "Nominal and temporal anaphora", which appeared in Linguistics and Philosophy in 1984 and which, because of its exceptional lucidity, as well as perhaps the prominent place in which it appeared and the reputation of its author, appears to have had a strong and lasting influence on formal theories of tense and aspect and on current perceptions of their early history. Partee is most generous in referring to what she saw as the contribution my work had made to the account she presents in this paper, but in a way that generosity may have enhanced the misunderstanding I am referring to. The overall picture that emerges from her paper is one which credits me with the development of Discourse Representation Theory as a framework for dealing with donkey pronouns and related phenomena of pronominal reference and anaphora, of which Partee's paper makes a novel and extended use by applying it to the formal analysis of tense. (Partee also cites Hinrichs' closely similar proposal for dealing with tense in a dynamic framework.)

Partee also mentions a somewhat earlier paper of mine, "Events, instants and temporal reference" (1979), which contains some hints in the direction of a dynamic treatment of tense in discourse. However, this paper is primarily concerned with a closely related but nevertheless nonidentical topic: using the so-called "Russell-Wiener construction" (see section III of this paper) to explicate the concepts of "punctuality" and "durativity" that have been invoked by French grammarians in their attempts to capture the differences 
between the two past tenses of French known as the passé simple and the imparfait. The passé simple, it is held in many of these characterizations, is a tense that conveys punctuality whereas the imparfait conveys durativity. "Events, instants and temporal reference" argues that an intuitively adequate formal explication of the notions of punctuality and durativity as they figure in these accounts requires a level of discourse representation. Discourse Representation Structures, in the technical sense of the term developed in "A theory of truth and semantic representation" (1981a) and in the present paper, are representations at that level. But "Events, instants and temporal reference" doesn't develop an account of how discourse representations for natural language sentences and discourses can be constructed in the way this is done in "A theory of truth and semantic representation" and the present paper (as well as, of course, in Partee's "Nominal and temporal anaphora").39

It is not hard to see how all this could have led to the impression that DRT was originally developed for the sole purpose of dealing with issues in the domain of pronominal anaphora and that it was only subsequently adapted for use in accounts of the behavior of tense. But in fact that was not the order in which things actually happened, and in this case putting the record straight is, as I see it, not just a matter of pointing out who did what when. The primary issue here is the original point and raison d'être of DRT. The original motivation for postulating a semantic representation level of the kind assumed in DRT was the conviction that a formally precise and intuitively plausible explication of the punctuality-durativity contrast was possible only in terms of representations at this level. It was this conviction which led to the explorations of "Events, instants and temporal reference". But the proposal made in that paper - that the relevant notion of punctuality has to be defined in terms of a time structure determined by the discourse representation, a much impoverished time structure when compared with the time of the real world - is incomplete as an account of the difference of passé simple and imparfait so long as the contributions of those tenses to the discourse representations that determine the relevant interpretations of punctuality and durativity haven't been made fully explicit: what the account should establish is that the events contributed by passé simple sentences emerge as punctual in the sense of the "discourse time structures" determined by the representations of the discourses that contain those sentences and that this is in general not so for the eventualities contributed by imparfait sentences.

39 For more on the connection between Partee's work and the paper "Events, discourse representation and temporal reference" and its origins, see Partee's commentary (2017). 
Events, discourse representations and temporal reference

But that requires an account of the construction of such representations from tensed discourses, in which the semantic contributions of passé simple and imparfait are made fully explicit.

Postulating a level of discourse representation is one thing, but spelling out how discourse representations can be constructed in a systematic way from the discourses they represent is quite another. That task was already at the top of the agenda in the summer of 1978, when "Events, instants and temporal reference" was written - how could it not have been! But the awareness that the task needed to be carried out if the approach of "Events, instants and temporal reference" was to be viable at all presented me with a dilemma, which lasted from the summer of 1978 till the spring of 1980. For someone like me, who was committed to Montague Grammar as "the" way to do natural language semantics, adopting a level of discourse representation in addition to the syntactic structures of object language expressions (e.g., expressions of some suitable fragment of French) and the models of model-theoretic semantics seemed a momentous step, which should be taken only for very good and compelling reasons. And analyzing certain sentence elements (viz., the tenses of the verb) as transsentential anaphoric devices was also at odds with the prevalent conception at that time of the kinds of semantic contributions that a sentence constituent could be expected to make.

For this reason the discovery that an analysis similar to the one I had come to see as necessary for the tenses of French and other languages was possible and illuminating also for an intuitively very different kind of expression, viz., pronouns, came as a kind of liberation: now there were two different kinds of phenomena, tenses and pronouns, belonging to apparently very different parts of the grammar, which seemed to function in much the same way and to require a similar revision of the central principles of model-theoretic semantics as they had been stated and exemplified by Montague (1970a, 1970b, 1973). And the architectural overhaul needed for what I wanted to say about tenses now no longer seemed quite as far-fetched, and also, perhaps, not quite as difficult to sell. $4^{\circ}$

40 As such the analogies between pronouns and tenses were of course no novelty. In 1973, Partee had already made a persuasive case for certain similarities between them (see Partee 1973). As I write this I cannot reconstruct how much her ideas influenced me during the period of which I am speaking. I cannot even remember whether I had read her 1973 paper; but for circumstantial reasons it seems extremely unlikely to me that I had not. 
The decision to present the first explicit formulation of DRT in the way this was done in "A theory of truth and semantic representation", with its exclusive focus on donkey anaphora and without any reference to tense, was largely a strategic one. Donkey anaphora was a problem that a number of semanticists were thinking about at the time and for which alternative proposals had recently been put forward and widely discussed. Furthermore, donkey pronoun anaphora is found within single sentences, and it was as a sentence-internal phenomenon that the problem had been presented to the semantics community by Geach (1962) and had been generally perceived since. By emphasizing the similarities between the classical cases of donkey anaphora that we associate - then as now - with the name of Geach and the discourse-anaphoric behavior of pronouns it was possible to make a plausible case for a discourse semantics along the lines of DRT; and that was the line that "A theory of truth and semantic representation" took. ${ }^{41}$

As a strategic ploy the decision to focus exclusively on nominal reference and anaphora in "A theory of truth and semantic representation" may well have been the right one. I have no doubt that it was what "A theory of truth and semantic representation" had to say about the sentence-internal cases of donkey anaphora that made semanticists pay attention and that it was the close parallels which the theory draws between sentence-internal and transsentential cases of pronoun anaphora that enabled it to make plausible to some at least that a formally precise discourse semantics was both needed and possible.

But the exclusive focus on pronominal anaphora also had a drawback. One criticism of the general approach of "A theory of truth and semantic representation", which was articulated by Groenendijk \& Stokhof and which for them became a starting point for their own unified treatment of sentenceinternal and discourse-level nominal anaphora, was that the representational part of the DRT approach could be dispensed with so long as one was prepared to make some other fundamental changes to the semantic framework, by replacing some of the central semantic concepts of model-theoretic semantics, such as "truth" and "proposition", by new ones like "context change

41 I have no reason to think that the paper was the first to press the point that some kind of systematic discourse semantics was needed. But to my knowledge there were no formally precise proposals for discourse semantics at that time, let alone proposals that came with a demonstration of how they work out in detail for particular cases. (At that particular point I hadn't yet become aware of Heim's simultaneously but independently developed File Change Semantics.) And on the other hand, in none of the extant proposals for solving the donkey problem did discourse play a part comparable to the one it was made to play in DRT. 
Events, discourse representations and temporal reference

potential" and "information state". Many found that criticism persuasive and the Dynamic Semantics that Groenendijk \& Stokhof developed as an alternative to DRT soon found many adherents. Looking back now it seems to me that one of the reasons why the argument against the representational dimension of DRT could have held as much sway as it appears to have done was that in the ensuing debate one important ingredient was missing. Missing was precisely that which had been the initial impetus for wanting a level of discourse representation in the first place: the conviction that such a level was indispensable to a formal explication of the punctuality-durativity contrast that French grammarians had invoked in their attempt to explain the difference between imparfait and passé simple. And the absence of that consideration from the debate was fostered, I suspect, because there was no prominently visible bridge crossing the gap between "Events, instants and temporal reference", in which the conceptual need for a level of discourse representation was argued, and "A theory of truth and semantic representation", which lays out the formal syntactic and semantic details of a particular discourse representation formalism (or "DRS-language") and the methods of constructing representations in this DRS-language from particular sentences and bits of discourse, but which says nothing whatever about time and tense.

The Langages paper was intended to be that bridge. It was conceived as a companion piece to "A theory of truth and semantic representation" and as a sort of antidote to a one-sided perception of DRT as a theory of pronominal anaphora and nothing else. Although written after "A theory of truth and semantic representation", it occupies a kind of middle ground between it and "Events, instants and temporal reference" in that it focusses on the application of DRT to temporal reference, with specific proposals for the semantic processing of passé simple and imparfait, while staying clear of all the complexities that arise for the DR-theoretic method when it is extended to logical operators such as negation, disjunction, conditionals and universal quantification (which give rise to what I still see as the most interesting logical aspects of DRT as a general framework for the representation of information, but are of no directly visible relevance to the semantics of tense).

Unfortunately, the publication of the French version of "Events, discourse representations and temporal reference" seems to have done little to forestall the misunderstanding that can hardly fail to arise when "A theory of truth and semantic representation" is read in isolation from the issues in temporal semantics that eventually led to it. There are probably several reasons for this. Perhaps the most important one was the content-unrelated fact that the 
paper appeared in the wrong language and in the wrong place. Then as now, papers in our field have little chance of making a wide impact unless they are written in English, and I suspect that by and large Langages has never had a great deal of currency within the world of formal semantics. (Moreover, the Langages version uses uninvitingly small print - it takes twenty-five small size pages, as compared to the fifty-eight pages of the present version (or fifty-four if the frontmatter and preface to the appendix are ignored), and especially the formulas contain a distressing number of misprints. I hope I have caught and eliminated the vast majority of those in the present English version. My apologies for all those that may still be there. But believe me, there are many more in the original French version as it appeared in 1981.)

But there are also more intrinsic reasons why people may have had a strong inclination to ignore this paper or to put it aside after a superficial perusal. One is that the paper brings into play something that was much on my mind at the time when it was written and which is also prominent in "Events, instants and temporal reference", but which has never become an integral part of the tense-and-aspect literature. This is vagueness. One of the convictions I had then (and to which I have actively returned in recent times) is that certain aspects of vagueness can and should be handled at the representational level which DRT makes available. But nothing much was done with this idea at the time (or, for that matter, has been since). Of course, even if vagueness is kept out of the semantic representations it may still be relevant in that it manifests itself at the level of the models for the representation language, and that is in fact the line that "Events, instants and temporal reference" takes. But the particular role that vagueness is made to play in the present paper is not a happy one. There are various places where issues connected with vagueness are brought up. But since in the formal definition of truth given in the appendix vagueness doesn't play any real part, the earlier remarks on vagueness and its formalization must come across to the reader as ultimately irrelevant add-ons, which should have been kept for some other occasion. Another distraction, also concerned with vagueness but closer to the central topic of the paper, is the fairly extensive discussion of interval semantics, and its implications for partiality.

Unattractive also, given the central purpose of the paper, is the syntax that the appendix specifies for the fragment of French that is defined there (and for which the appendix then gives an explicit definition of DRS-construction for its sentences and discourses). The way the syntax is set up must have impressed most readers as home-baked and idiosyncratic. 
Events, discourse representations and temporal reference

Another infelicity is that the construction algorithm of the appendix works for the limited fragment for which it is given only because the fragment is so very restricted; extending the fragment would require substantial modification of the algorithm.

And, finally, there are a number of aspects to the definition of the models for the DRS-language that cannot but have impressed the reader as poorly motivated but for which no intuitive justification is provided. ("Why", one can almost see the reader think, "should the models be set up in precisely this way and not in some other?")

All in all I feel now that the appendix is the least attractive and least successful part of the paper. But I have included it in the present version nevertheless, not only because it is there in the published version of Langages, but also because it is an essential part of the paper from the "historical" perspective that I mentioned at the outset of this postscript: it is only in the appendix that the central purpose of the paper - trying to do for tenses and other temporal devices of natural language what "A theory of truth and semantic representation" attempts for pronouns and other noun phrases in an essentially tense-free setting - becomes formally explicit.

In preparing the present document I have had to rely on the only version of the original English manuscript that, after so many years, I was able to lay my hands on: a photocopy of a typescript with some corrections in my own handwriting (quite a few of which proved to be nearly undecipherable for their author). Three pages were missing from this copy, and there I have had to translate back from the French. The only part where I have taken some liberties is the appendix. Here my sources were not fully consistent. I have done my best to maintain coherence while staying as close as I could to what could be reconstructed as the original version, but at the same time I have made small changes where I thought this would substantially improve understandability. I do not think that the few liberties I have taken with the appendix have led to any change of substance or distorting embellishment in hindsight. In any case, the point of including the formal fragment description of the appendix is not to provide a platform for the claim that the issues that the appendix deal with were sorted out without remainder at that point in time - they were not, as I have indicated more than once - but rather that at the time when the paper was published the need for and possibility of a formal account of the transclausal semantic properties of tenses were an explicit part of the agenda. 
In all other respects the present version is a faithful rendering of the original English, with no other deviations than the occasional (but always content- or gist-preserving) change of a word or an interpunction.

\section{References}

Bennett, Michael R. \& Barbara Hall Partee. 1978. Toward the logic of tense and aspect in English. Bloomington: Indiana University Linguistics Club.

Burgess, John P. 1979. Logic and time. The Journal of Symbolic Logic 44(4). 566-582. https://doi.org/10.2307/2273296.

Cocchiarella, Nino B. 1966. Tense and modal logic: A study in the topology of temporal reference. UCLA PhD Thesis.

Davidson, Donald H. 1967. Truth and meaning. Synthese 17(3). 304-323. https: //doi.org/10.1007/BFoo485035.

Davidson, Donald H. 1980. Essays on actions and events. Oxford: Clarendon.

Dowty, David R. 1979. Word meaning and Montague Grammar: The semantics of verbs and times in Generative Semantics and in Montague's PTQ (Synthese Language Library 7). Dordrecht: D. Reidel. https://doi.org/10.1007/ 978-94-009-9473-7.

Evans, M. Gareth J. \& John H. McDowell (eds.). 1976. Truth and meaning: Essays in semantics. Oxford: Clarendon.

Fine, Kit. 1975. Vagueness, truth and logic. Synthese 30(3-4). 265-300. https: //doi.org/10.1007/BFo0485047.

van Fraassen, Bas C. 1969. Presuppositions, supervaluations, and free logic. In J. Karel Lambert (ed.), The logical way of doing things, chap. 4, 67-91. New Haven \& London: Yale University Press.

Geach, Peter Thomas. 1962. Reference and generality: An examination of some medieval and modern theories. Ithaca \& London: Cornell University Press.

Groenendijk, Jeroen A. G. \& Martin J. B. Stokhof. 1991. Dynamic predicate logic. Linguistics and Philosophy 14(1). 39-100. https://doi.org/10.1007/ BFoo628304.

Heim, Irene R. 1982. The semantics of definite and indefinite noun phrases. 2011 edition. University of Massachusetts at Amherst PhD Thesis. http: //semanticsarchive.net/Archive/jA2YTJmN.

Hinrichs, Erhard W. 1981. Temporale Anaphora im Englischen. EberhardKarls-Universität Tübingen Staatsexamen thesis.

Hornsby, Jennifer. 1978. Actions. University of Cambridge PhD Thesis. 
Events, discourse representations and temporal reference

Kamp, Hans. 1975. Two theories about adjectives. In Edward L. Keenan (ed.), Formal semantics of natural language: Papers from a colloquium sponsored by the King's College Research Centre, Cambridge, 123-155. Published under the name J. A. W. Kamp. Cambridge, U.K.: Cambridge University Press. https://doi.org/10.1017/CBO9780511897696.011.

Kamp, Hans. 1976. Quantification and reference in modal and tense logic. In Siegfried J. Schmidt (ed.), Pragmatik/Pragmatics II: Zur Grundlegung einer expliziten Pragmatik, 158-197. München: Wilhelm Fink Verlag.

Kamp, Hans. 1979. Events, instants and temporal reference. In Rainer Bäuerle, Urs Egli \& Arnim von Stechow (eds.), Semantics from different points of view (Springer Series in Language and Communication 6), 376-417. Berlin: Springer. https://doi.org/10.1007/978-3-642-67458-7_24.

Kamp, Hans. 1980. Some remarks on the logic of change, Part I. In Christian Rohrer (ed.), Time, tense, and quantifiers: Proceedings of the Stuttgart Conference on the Logic of Tense and Quantification (Linguistische Arbeiten 83), 135-179. Tübingen: Max Niemeyer. https://doi.org/10.1515/ 9783111346069.135.

Kamp, Hans. 1981a. A theory of truth and semantic representation. In Jeroen A. G. Groenendijk, Theo M. V. Janssen \& Martin J. B. Stokhof (eds.), Formal methods in the study of language: Part 1 (Mathematical Centre Tract 135), 277-322. Amsterdam: Mathematisch Centrum.

Kamp, Hans. 1981b. Evénements, représentations discursives et référence temporelle. Langages 15(64). 39-64. https://doi.org/10.3406/lgge.1981. 1884.

Klein, Ewan H. 1981. The interpretation of adjectival, adverbial and nominal comparatives. In Jeroen A. G. Groenendijk, Theo M. V. Janssen \& Martin J. B. Stokhof (eds.), Formal methods in the study of language: Part 1 (Mathematical Centre Tract 135). Amsterdam: Mathematisch Centrum.

Montague, Richard M. 1970a. English as a formal language. In Bruno Visentini (ed.), Linguaggi nella società e nella tecnica (Saggi di cultura contemporanea 87), 189-224. Reprinted in Thomason 1974, chap. 6, 188-221. Milan: Edizioni di Comunità.

Montague, Richard M. 1970b. Universal grammar. Theoria 36(3). Reprinted in Thomason 1974, chap. 7, 222-246, 373-398. https://doi.org/10.1111/j.17552567.1970.tboo434.x.

Montague, Richard M. 1973. The proper treatment of quantification in ordinary English. In Patrick Suppes, Julius M. E. Moravcsik \& Jaakko Hintikka (eds.), Approaches to natural language: Proceedings of the 1970 Stanford 
Workshop on Grammar and Semantics (Synthese Library 49), 221-242. Reprinted in Thomason 1974, chap. 8, 247-270. Dordrecht: D. Reidel. https://doi.org/10.1007/978-94-010-2506-5_10.

Nef, Frédéric. 1980. Les verbes aspectuels du français: Remarques sémantiques et esquisse d'un traitement formel. Semantikos 4(1). 11-46.

Parsons, Terence D. 1970. Some problems concerning the logic of grammatical modifiers. Synthese 21(3-4). 320-334. https://doi.org/10.1007/ BFoO484803.

Partee, Barbara Hall. 1973. Some structural analogies between tenses and pronouns in English. The Journal of Philosophy 70(18). 601-609. https: //doi.org/10.2307/2025024.

Partee, Barbara Hall. 1984. Nominal and temporal anaphora. Linguistics and Philosophy 7(3). 243-286. https://doi.org/10.1007/BFoo627707.

Partee, Barbara Hall. 2017. A note on temporal reference, anaphora, and Kamp's motivations for DRT. Semantics \& Pragmatics 10(2n). 1-4. https: //doi.org/10.3765/sp.10.2n.

Russell, Bertrand Arthur William. 1914. Our knowledge of the external world as a field for scientific method in philosophy. Chicago \& London: Open Court.

Thomason, Richmond H. (ed.). 1974. Formal philosophy: Selected papers of Richard Montague. New Haven \& London: Yale University Press.

Vendler, Zeno. 1957. Verbs and times. The Philosophical Review 66(2). 14316o. https://doi.org/10.2307/2182371.

Verkuyl, Henk J. 1972. On the compositional nature of the aspects (Foundations of Language 15). Dordrecht: Springer. https://doi.org/10.1007/978-94017-2478-4.

Wiener, Norbert. 1914. A contribution to the theory of relative position. Proceedings of the Cambridge Philosophical Society 17(5). 441-449.

Wittgenstein, Ludwig J. J. 1922. Tractatus logico-philosophicus. Translated by Charles Kay Ogden. London: Kegan Paul, Trench, Trubner \& Co.

Hans Kamp

Institut für maschinelle

Sprachverarbeitung

Universität Stuttgart

Pfaffenwaldring $5 b$

D-70569 Stuttgart

jaw.kamp@gmail.com 